\title{
Jurassic dinosaur tracks and trackways of the Cleveland Basin, Yorkshire: preservation, diversity and distribution
}

\author{
M. RomANO ${ }^{1}$ and M. A. WHYTE \\ ('Presidential addresses delivered at York, 4th December, 1999, and 2nd December, 2000) \\ Department of Geography, Dainton Building, Brookhill, University of Sheffield, Sheffield S3 7HF \\ (e-mail:m.romano@sheffield.ac.uk; m.a.whyte@sheffield.ac.uk)
}

\begin{abstract}
SUMMARY: Dinosaur tracks are abundant in the Middle Jurassic rocks of Yorkshire and indeed characterize the non-marine sequences developed within the Cleveland Basin. These tracks and associated trackways provide valuable evidence of the possible diversity of the dinosaur communities, their potential makers and behaviour and useful insights into the habitats and palaeoenvironment during the time of deposition. The uneven historical development of research into Yorkshire dinosaur tracks is reviewed and the Middle Jurassic lithostratigraphy, biostratigraphy and chronostratigraphy of the region is outlined. Next, the probable palaeoenvironment of the Middle Jurassic Cleveland Basin, generally regarded as a coastal plain and fluvial complex, is briefly summarized. The terminology used to describe the dominant preservational types of dinosaur tracks, such as surface, transmitted and underprints, is clearly defined, with examples from the Yorkshire sequences. The Yorkshire tracks show considerable morphological diversity and at present 29 different morphotypes have been recognized, which possibly represent at least 15 ichnotaxa. These morphotypes include both quadrupedal and bipedal forms, as well as a distinctive suite of raking prints resulting from swimming activity. The distribution and abundance of the known dinosaur tracks within the Middle Jurassic rocks of Yorkshire is described. For the first time, a range chart of dinosaur tracks is presented that illustrates the persistence of some morphotypes throughout the Ravenscar Group (Middle Jurassic) of the Cleveland Basin. Track distribution and diversity data allow reconstruction of the Yorkshire dinosaur communities that were made up of between 7-10 common types, belonging to sauropods, stegosaurids, ornithopods and theropods. The area is a 'megatracksite' of global importance.
\end{abstract}

Dinosaur remains from the Middle Jurassic of Yorkshire are very rare (Williamson 1837; Fox-Strangways 1904; Benton 1996) and reflect the poor global record of the group at this time, particularly in the Aalenian (Romer 1966; Weishampel et al. 1990; Benton 1993). The single reported find of bone assigned to the sauropod Cetiosaurus from the marine Scarborough Formation (Williamson 1837; Fox-Strangways 1904) still remains the only published occurrence of dinosaur skeletal elements from the Middle Jurassic of this area. However, dinosaur tracks and trackways are very common and these can provide valuable evidence of the possible diversity of the dinosaur communities, their potential makers and behaviour, and useful insights into the palaeoenvironment during the time of deposition (Thulborn 1990; Lockley 1991b).

Recent work on dinosaur prints by the authors has shown that there is a wide range of print morphotypes from the Yorkshire Middle Jurassic succession, which indicates the former presence of varied dinosaur communities (Whyte \& Romano 1981, 1993, 1995, 2001, 2002; Romano \& Whyte 1996; Romano et al. 1999). As regular visitors to the east coast over the past 15 years we have produced a comprehensive database on the variety and occurrence of these ichnites. Extended detailed surveys of the coastal exposures with volunteers from Earthwatch International started in 1996. These, together with numerous geological field excursions and individual contributions from colleagues and co-workers too numerous to mention, have also added to these records. More specifically, a Dinosaur Track Research Group (DTRG) has been estabished at the University of Sheffield, which has overseen a number of $\mathrm{PhD}$ projects on field and laboratory studies of

(c) Yorkshire Geological Society, 2003 the tracks. These personnel and their contributions will be identified below.

Following a brief historical review, an outline of the Middle Jurassic lithostratigraphy, biostratigraphy and chronostratigraphy of the region will be presented; after which the Middle Jurassic palaeoenvironment will be described. Then follows an account of the terminology used to describe the dominant preservational types of dinosaur tracks encountered. Finally, three aspects of the dinosaur tracks of Yorkshire will be investigated; track diversity, track distribution and abundance and possible dinosaur diversity. Although in this review relatively few of the tracks are named, this is not meant to signify an aversion to this practice. Indeed, the naming of tracks allows easy reference to any previously named ichnite in the literature (McAllister 1989, p. 4) and, by using the currently adopted 'binomen' system based on the Linnean classification, may indicate close morphological similarity or dissimilarity. However, at this stage of these studies, in particular with reference to the tridactyl tracks, it is preferential to identify different unnamed morphotypes that may, with more work, become the basis of more formal ichnotaxa. This work on the behaviour patterns of these dinosaurs, as deduced from track morphology, configuration of the trackways and habitats, will be addressed at a later date.

\section{HISTORICAL REVIEW OF TRACK RESEARCH}

It is now nearly 100 years since definite dinosaur tracks were first described from the Middle Jurassic rocks of Yorkshire (Brodrick 1907), the 'true starting-point of British Jurassic palaeoichnology' (Sarjeant in Casamiquela et al. 1987, p. 5). In 
fact they had probably been observed around 1895 , since it is reported (Hargreaves 1913, p. 92) that a 'Mr. Rowntree obtained a footprint from Cayton Bay [south of Scarborough], which Mr Lamplugh pronounced to be probably crocodilian'. Despite their early recognition in this area, though considerably later than the first finds of Triassic prints elsewhere in the country (Sarjeant 1974), there has not been a consistent flow of publications on these emotive yet enigmatic trace fossils. Papers published on Yorkshire dinosaur tracks over the last 100 years show a strongly bimodal production rate (Fig. 1). Following an initial rush in the early part of the 20 th century, that coincided with $\mathrm{H}$. C. Beasley's investigations in the Triassic of Cheshire (Sarjeant 1974), numbers of papers declined until the 2nd World War and did not increase again until the mid-1970s.

This dearth of papers between 1920-1970 on the Yorkshire dinosaur tracks is recognized in two comprehensive accounts by Sarjeant (1974) and Delair \& Sarjeant (1985) on the history of the study of fossil vertebrate footprints in the British Isles. In these works, Jurassic Yorkshire dinosaur prints occupy a combined total of just over four pages of text and 13 references, whereas the Triassic Cheshire/Lancashire prints merit over 21 pages of text and in excess of 100 references (although, admittedly, Beasley contributed 19 of the latter!). It is difficult to pinpoint why, following the initial recognition and subsequent publications, the interest in these Yorkshire dinosaur tracks was not sustained, at least with regards to published

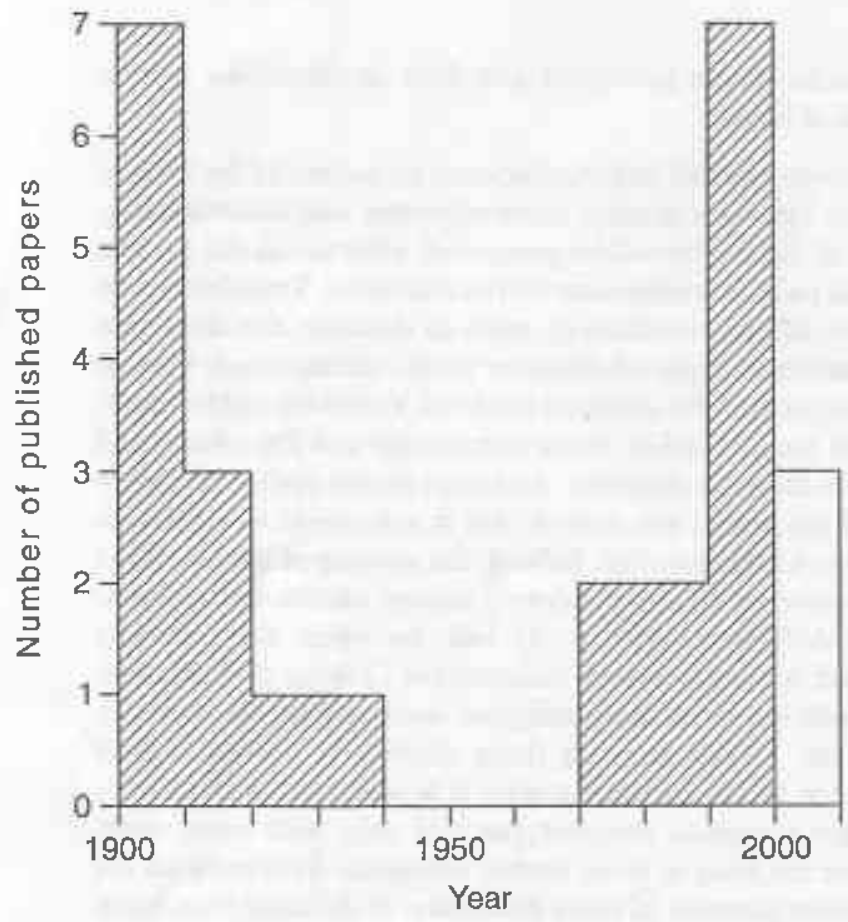

Fig. 1. Bar chart showing numbers of publications on dinosaur tracks of the Middle Jurassic rocks of the Cleveland Basin, Yorkshire per decade over the last century (References used to construct bar chart: Brodrick 1907, 1908, 1909a, 1909b; Sheppard 1908; Kendall 1908; Hargreaves 1913, 1914; Fox-Strangways \& Barrow 1915; Kendall \& Wroot 1924; Black et al. 1934; Sarjeant 1970, 1974; Delair \& Sarjeant 1985; Ivens \& Watson 1994; Whyte \& Romano 1993, 1994, 1995, 2001, 2002; Romano \& Whyte 1996, present paper; Romano et al. 1999; Rawson \& Wright 2000). Papers published or in press after 2000 are . shown unornamented. accounts. Certainly dinosaurs had not become significantly less fashionable, nor was there any lack of active work on dinosaur tracks elsewhere in the world, since this was the time (between 1939-1954) that Roland T. Bird published a series of popular articles on the subsequently famous sauropod trackway at the Paluxy River site in Texas, USA (descriptions and references in Farlow \& Lockley 1989; Farlow et al. 1989; Lockley \& Hunt 1995). So why did British workers not fully exploit the rich pickings of dinosaur tracks on the east coast? Part of the reason may have been that tracks were regarded as rare and, indeed, when the present authors started work on the Middle Jurassic dinosaur tracks of Yorkshire (Whyte \& Romano 1981), there was little indication as to the wealth of material that would come to light. However, it soon became apparent to us that dinosaur tracks, far from being just scattered or relatively localized occurrences, actually characterize many of the non-marine rock sequences of this area. They occur throughout the Middle Jurassic, often in considerable numbers and in a variety of facies. Thus the early records that gave the impression that prints tended to occur at particular horizons or beds, such as the 'footprint bed' at Burniston (Hargreaves 1914) and the 'Unio bed' at Whitby (Kendall 1908), are now known to be rather biased views and do not reflect the true picture.

Another reason for their unpopularity (though certainly not peculiar to Yorkshire) may have been that the full potential of the tracks was not appreciated. Hence the early papers on the tracks of the east coast (Brodrick 1907, 1908, 1909a, 1909b; Kendall 1908; Hargreaves 1913, 1914; Fox-Strangways \& Barrow 1915; Black el al. 1934) dealt mainly with print shape and assignment to particular dinosaur groups. Yet, apart from possibly enabling the maker to be identified (though in fact this is probably rather rare), the tracks also may provide information on the size of the animal (hip height, gleno-acetabular distance) and its behaviour (mode of locomotion, gait, speed). Also tracks may supply evidence on abundance, diversity, and ecology (gregarious nature, migratory pathways, preferred habitat), as well as yielding information on the state of the substrate during footprint formation. Pioneering work by Alexander $(1976,1985)$ also showed that the speed of locomotion could be deduced from their trackways.

A further reason for the apparent unpopularity of the prints may stem from their occurrence. They are most commonly found on the coastal exposures, often on loose boulders close to the steep unstable cliffs; specimens commonly fail to survive the winter storms; access to some of the beach localities is difficult, or at least unpopular to the casual day visitor; the lure of Early Jurassic ammonites, belemnites, bivalves and marine reptiles is too distracting. Whatever the reason(s), interest certainly did decline during the middle of the 20th century, and it was not until the 'current dinosaur track renaissance' (Lockley 1991a, 1991b, 1998; Lockley \& Meyer 2000 , p. xii) that it has returned again. Papers became more numerous in the early 1990 s (Whyte \& Romano 1993 , $1994,1995)$ including a very useful publication by Ivens \& Watson (1994) that listed and described many of the published (and unpublished) finds from the Yorkshire coast. It is hoped that the encouraging present upsurge in publications will continue and produce further revelations on these most appealing of fossils, since we believe that studies of the dinosaur tracks in the Yorkshire area are particularly important owing to the scarce records of skeletal remains of dinosaurs from the Middle Jurassic. 


\section{STRATIGRAPHY}

The Jurassic rocks of Yorkshire share sufficiently distinct characters to warrant recognition as a single depocenter. This area was generally known as the Yorkshire Basin (Fox-Strangways 1892 , p. 388), although more recently the term Cleveland Basin (Dingle 1971; Hemingway 1974; Bradshaw et al. 1992) has been adopted to restrict the region to north of the Coxwold-Flamborough Fault line. The Middle Jurassic rocks are well exposed along most of the coast from just south of Yons Nab to around Port Mulgrave in the north, a distance of approximately $55 \mathrm{~km}$ (Fig. 2), whereas inland exposures tend to be uncommon.

\subsection{Lithostratigraphy}

The Lower Jurassic rocks of the Cleveland Basin were folded during late Early Jurassic (Toarcian) times into a series of lowamplitude basins and domes (Hemingway 1974). This event was followed by a period of widespread erosion to produce a nearly level surface on which Middle Jurassic rocks lie unconformably. The Middle Jurassic rocks, depositing under fluctuating non-marine and marine conditions, were subdivided by Fox-Strangways (e.g. 1880, p. 3) into Lower, Middle and Upper Estuarine series separated by marine units. These subdivisions were later renamed and modified by Hemingway (1949), who introduced the terms Lower, Middle and Upper Deltaic series which are underlain by the marine Dogger. Some years later Hemingway \& Knox (1973) applied a more formal lithostratigraphical terminology to the Middle Jurassic sequence of the Cleveland Basin and it is this (Fig. 3) that has essentially been adopted and used by subsequent authors.

The dominantly non-marine Ravenscar Group (c. $240 \mathrm{~m}$ thick) overlies the Dogger Formation (or marine Lias where the latter is absent) and consists in the main of shaly mudstones, sandstones, siltstones, rare impure coals and ironstones that constitute three major non-marine units, the Saltwick, Cloughton and Scalby formations, which are $57 \mathrm{~m}$, $85 \mathrm{~m}$ and $60 \mathrm{~m}$ thick respectively. Separating these units are two main marine units, the Eller Beck and Scarborough formations, together with a locally developed marine unit

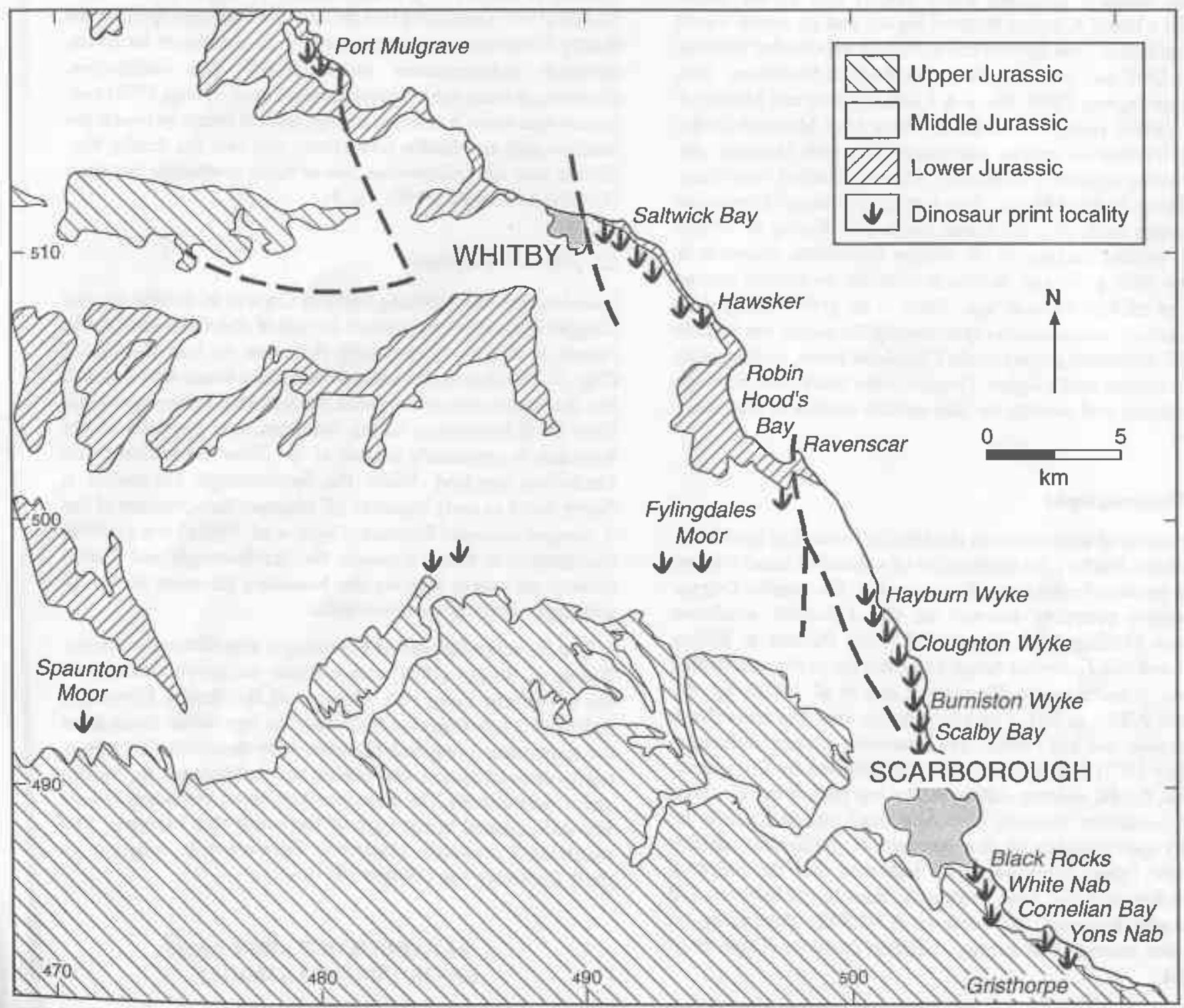

Fig. 2. Simplified geological map of eastern Yorkshire between Port Mulgrave and Gristhorpe, showing localities mentioned in the text and principal sites where dinosaur prints have been recorded. 


\begin{tabular}{|c|c|c|c|}
\hline STAGE & \multicolumn{3}{|c|}{ LTHOSTRATIGAAPHY } \\
\hline \multirow[t]{4}{*}{ BATHONIAN } & \multirow[b]{4}{*}{ Plavenecar } & \multirow{2}{*}{ Scalty Fomalion } & Lang Nab Member \\
\hline & & & Maer Bat Mambar \\
\hline & & Scart & Thation \\
\hline & & \multirow{3}{*}{$\begin{array}{l}\text { Clougition } \\
\text { Fommation }\end{array}$} & Enstrarpe Nember \\
\hline \multirow{2}{*}{ BAJOCIAN } & \multirow[t]{4}{*}{ Group } & & $\begin{array}{l}\text { Leboerston } \\
\text { Mamtor : }\end{array}$ \\
\hline & & & Sycarhans Member \\
\hline \multirow{3}{*}{ AALENIAN } & & \multicolumn{2}{|c|}{ Eler Beck Famasogn? } \\
\hline & & \multicolumn{2}{|c|}{ Battwick Foematen } \\
\hline & \multicolumn{3}{|c|}{ Dogger Fannalion } \\
\hline
\end{tabular}

Fig. 3. Lithostratigraphy and chronostratigraphy of the Middle Jurassic rocks of the Cleveland Basin (modified from Rawson \& Wright 2000). Marine units are stippled. Note that thicknesses of units are not drawn to scale.

(Lebberston Member) in the Cloughton Formation in the south of the area. Hemingway \& Knox (1973) did not formally name subdivisions in the Scalby Formation ("Upper Estuarine/ Deltaic Series'), although Black (1929) had earlier documented a lower 'Current Bedded Series' and an upper 'Level Bedded Series', the former being further subdivided into the 'Moor Grit' and overlying 'Current Bedded Sandstone' (see also Hemingway 1974). Nami \& Leeder (1978) and Leeder \& Nami (1979) recognized a lower Moor Grit Member of the Scalby Formation and an overlying Long Nab Member, the latter being equated with Black's 'Current Bedded Sandstone' and 'Level Bedded Series'. The marine Cornbrash Limestone Formation rests on a burrowed (pers. obs; Riding \& Wright 1989), eroded surface of the Scalby Formation (Rawson \& Wright 2000, p. 9) and in turn is overlain by further marine units of Middle Jurassic age. Knox et al. (1991) recognized three major transgressive-regressive cycles within the Middle Jurassic lithostratigraphy of the Cleveland Basin, each starting with a marine unit ('upper' Dogger, Eller Beck, Scarborough formations) and passing up into paralic mudrocks and sandstones.

\subsection{Biostratigraphy}

The paucity of ammonites in the Middle Jurassic of the Cleveland Basin renders the application of a detailed zonal scheme based on these fossils virtually impossible. The marine Dogger Formation probably belongs to the Leioceras opalinum Biozone (Riding 1984; Knox et al. 1991; Palliani \& Riding 2000) and the Ludwigia haugi Sub-biozone of the succeeding Ludwigia murchisonae Biozone (Cope et al. 1980b, fig. 4a, column AB38, p. 20). The next marine unit, the Eller Beck Formation, has not yielded any ammonite faunas (SylvesterBradley 1953) but it was tentatively assigned by Cope et al. (1980b, fig. 4a, column AB38) to the top part of the Graphoceras concavum Biozone (top Aalenian) and in Knox et al (1991) questionably to the younger Hyperlioceras discites Biozone (basal Bajocian). This indicates that the Saltwick Formation was laid down during the duration of between 1-2 ammonite biozones, i.e. between $0.7-1.8 \mathrm{Ma}$ depending on different estimates of average biozone duration (Cope et al. 1980a).

The Lebberston Member (=Cayton Bay Beds of Richardson 1912 and Cayton Bay Formation of Cope et al. 1980b) of the Cloughton Formation has not yielded any ammonites, but on the basis of ostracods (Bate 1978) and foraminifera (Morris \& Coleman 1990) is assigned to the Hyperlioceras discites to Witchellia laeviuscula biozones (lower Bajocian) (Cope et al. $1980 b$ ). The topmost marine unit of the Ravenscar Group, the Scarborough Formation, has yielded ammonites indicating the presence of all three sub-biozones of the Stephanoceras humphriesianum Biozone (Parsons 1977; Cope et al. 1980b). Bate (1978), from his study of the ostracods, suggested that the lower part of the Scarborough Formation was deposited during the previous Emileia (Otoites) sauzei Biozone.

The marine Cornbrash Limestone Formation (Rawson \& Wright 2000; =Abbotsbury Cornbrash Formation of Rawson \& Wright 1995) of the upper Middle Jurassic overlies the Scalby Formation. Diagnostic ammonite faunas from the Cornbrash Limestone Formation on the coast indicate the presence of the Macrocephalites (Kamiokephalites) kamplus Sub-biozone of the M. (M.) macrocephalus Biozone (Wright 1968). Thus the Scalby Formation could span at least 11 ammonite biozones, i.e. a duration of c. 8-10 Ma. Alternatively, rapid deposition and a break below the Cornbrash Limestone Formation could indicate that significantly fewer ammonite biozones are present (Leeder \& Nami 1979). A palynological analysis by Riding \& Wright (1989) concluded that the depositional time span for the Scalby Formation was in the order of 11 ammonite biozones, although sedimentation was probably not continuous. However, a more recent palynological study (Hogg 1993) suggested that there is a major stratigraphical break between the Scarborough and Scalby formations, and that the Scalby Formation may only encompass two or three ammonite biozones (Hesselbo \& Jenkyns 1995, fig. 3).

\subsection{Chronostratigraphy}

Based on the chronostratigraphy in Cope et al. $(1980 a, b)$, the Dogger Formation-Ravenscar Group of the Cleveland Basin ranges in age from the early Aalenian to late Bathonian (Fig. 3). The Aalenian/Bajocian boundary is not well defined, but the above authors assigned the Saltwick (=Hayburn) and Eller Beck formations to the Aalenian, and the base of the Bajocian is tentatively placed at the Eller Beck/Cloughton Formation junction. While the Scarborough Formation is firmly dated as early Bajocian (T. blagdeni Sub-biozone of the S. humphriesianum Biozone; Cope et al. 1980b) the possible stratigraphical break between the Scarborough and Scalby formations makes locating the boundary between the lower and upper Bajocian problematical.

The Bajocian-Bathonian boundary is also difficult to locate. Riding \& Wright (1989) showed that the palynofloras from the lowermost Long Nab Member of the Scalby Formation indicated a late Bajocian to Bathonian age, while those from the uppermost Long Nab Member were dominated by terrestrially-derived spores and pollen and indicated a Bathonian age. Consequently, the Bajocian/Bathonian boundary is provisionally placed at the base of the Long Nab Member. The overlying Cornbrash Limestone Formation is assigned an early Callovian age (Wright 1977).

\section{PALAEOGEOGRAPHY AND ENVIRONMENTAL MODEL}

The rocks of the Ravenscar Group are now generally regarded as being a coastal plain and fluvial complex (Alexander 1989) 
with occasional marine intercalations. However, as pointed out by Eschard et al. (1991) and Rawson \& Wright (2000, pp. 8-9), some sedimentological features may also suggest a deltaic origin for parts of the sequence. From approximately late Aalenian (c. $177 \mathrm{Ma}$ ) to late Bathonian (c. $160 \mathrm{Ma}$ ) times this coastal plain complex occupied a large area over present day Yorkshire and extended eastward into the North Sea (Knox et al. 1991; Bradshaw et al 1992). The depocenter was bounded to the north and west by the Mid North Sea High and Pennine Landmass respectively (Fig. 4). These upland areas were probably the major source for the siliciclastic material (Alexander 1986) that accumulated to a thickness of over $200 \mathrm{~m}$ during this time interval. The generally southward sloping coastal plain (Alexander 1986) maintained connections with the open sea to the south and SE, allowing the periodic marine incursions to flood the area.

Within the non-marine units of the Ravenscar Group (Saltwick, Cloughton and Scalby formations), mudrocks generally dominate volumetrically, whereas medium- to finegrained sandstones are locally common; the latter occurring as sheets, lenses and in heterolithic packages with mudrocks. Thin, dark grey-black carbonaceous shaly mudstone units commonly form prominent and laterally persistent beds and sphaerosideritic mudrocks and sandstones are ubiquitous. Despite their historical importance (Hemingway \& Owen 1975) coals are not particularly common. The lithotypes of the three non-marine units are essentially the same, though vary in proportion. For example, a feature of the lowest Saltwick Formation is the marked lateral facies variation in the Whitby area (Alexander \& Gawthorpe 1993). To the east of Whitby the formation is dominated by mudrocks with intermittent ribbon sandstone bodies, whereas immediately west of the town (on the other side of the Whitby Fault) the formation is made up almost entirely of sandstone. Significant lateral and

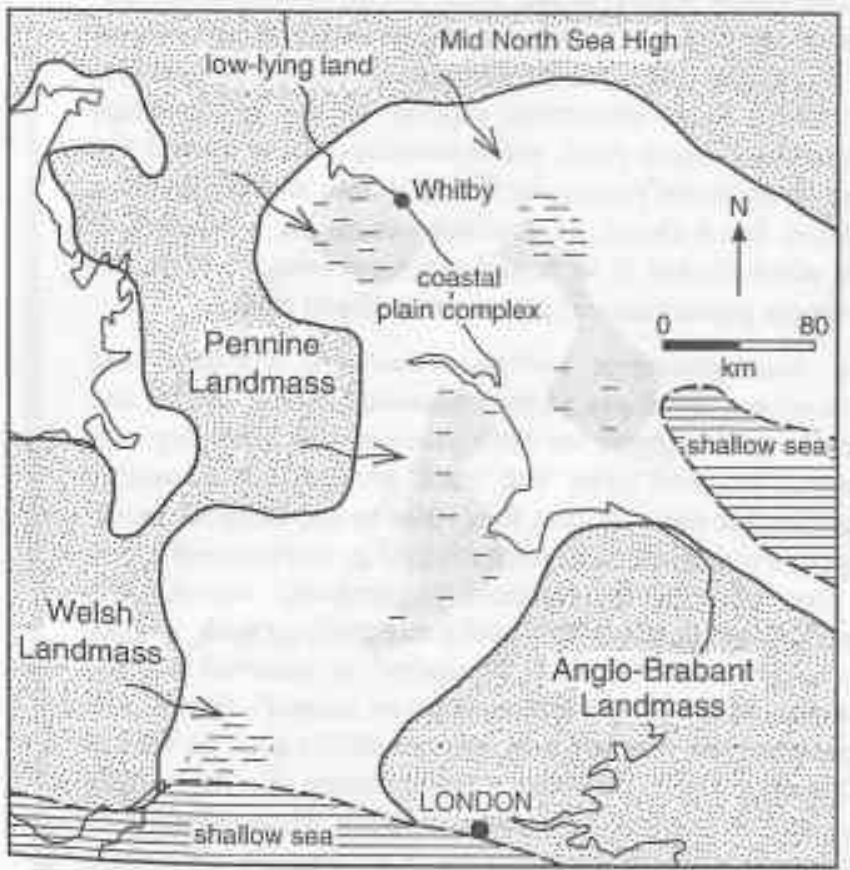

Fig. 4. Palaeogeographical map of northern England during Middle Jurassic times, showing extent of coastal plain complex, generalized sedimentary environments and directions of sediment derivation (after Knox et al. 1991; Bradshaw et al. 1992). vertical facies changes also occur in the Cloughton Formation. To the south of Scarborough, the marine Lebberston Member of the Cloughton Formation consists of a lower Millepore Bed and upper Yons Nab Beds. North of Scarborough, where the marine influence has diminished, the fully marine Yons $\mathrm{Nab}$ Beds have given way to the basal, quasi-marine part of the Gristhorpe Member (Rawson \& Wright 2000, p. 52). Also the Gristhorpe Member (the upper member of the Cloughton Formation) has few lenticular channel sandstones (Knox et al. 1991). In the youngest non-marine Scalby Formation, largescale cross-bedded sheet sandstones characterize the lower Moor Grit Member. The upper Long Nab Member consists of medium-scale cross-bedded sandstones with subordinate shaly mudstones, overlain by generally laterally persistent mudrock and sand-dominated heterolithic units, which may be traced for long distances (with minor changes) within the confines of a single bay, such as Burniston Bay (=Burniston Wyke). Yet where the sequence is interrupted by downcutting sandstone lenses or landslip areas it is generally difficult to correlate the lithostratigraphy in detail either side of the break in exposure.

Plant remains are extremely common and diverse (Konijnenburg-Van Cittert \& Morgans 1999) and occur as isolated drifted leaves (pteridophytes, pteridosperms, cycads, bennettitales, ginkgoales and conifers) transported logs, rootlets and in situ erect stems (Equisetum). Invertebrate body fossils, on the other hand, are very sparse; only bivalves and insect remains together with a single example of a fish (Hemingway 1974) have been recorded. The non-marine bivalve $U$ nio has been recorded from the Saltwick and Scalby formations, although bivalve escape structures (Lockeia) are much more common, widespread and locally prolific, Other invertebrate trace fossils, such as Cochlichnus, Protovirgularia, Beaconites (?= Taenidium) (Goldring \& Pollard 1995), Selenichnites (Romano \& Whyte 1987, 1990), Kouphichnium (Romano \& Whyte in press), 'Diplocraterion' and simple burrows are locally common.

The thick (up to a few metres) mudrocks may have accumulated in flood plains, shallow lakes and marshes, or abandoned river channels, whereas the coarser arenaceous rocks were deposited as sand bodies within river channels, levee and crevasse splay deposits (Hemingway 1974; Nani \& Leeder 1978; Livera \& Leeder 1981; Hancock \& Fisher 1981; Knox et al. 1991; Alexander 1986, 1987, 1989, 1992; Eschard et al. 1991; Alexander \& Gawthorpe 1993; Mjøs \& Prestholm 1993; Mjøs et al. 1993; Whyte \& Romano 2002). Rootlet beds bear testimony to soils capable of supporting luxuriant plant growth, and palaeosols with abundant sphaerosiderite indicate swampy conditions (Kantorowicz 1990). The general absence of coarse-grained sandstones and siliciclastic clasts suggests that, on the whole, the Middle Jurassic rocks of the Cleveland Basin, exposed along the Yorkshire coast, were deposited in an area of low available relief and relatively low flow regimes. The largest and most common clasts are carbonized plant fragments, mud flakes and reworked sideritized sedimentary pebbles, typically found as lag deposits at the base of channel sandstones; whereas at the base of scoured units within the Moor Grit Member, quartz pebbles occur (Nami \& Leeder 1978). Bone fragments in excess of $25 \mathrm{~cm}$ in length are very rare clast components. We have recorded large tree trunks up to $4.7 \mathrm{~m}$ in length from the Long Nab Member.

The highest and most persistent flow phases present during the deposition of these sedimentary sequences gave rise to the large-scale cross-bedded units in the Moor Grit Member, the 
downcutting of the channel systems that punctuate all three non-marine units, and the stacked sandstone channels of the Saltwick Formation to the west of Whitby (Alexander \& Gawthorpe 1993). Shorter-lived, high energy regimes resulted in the event beds that correspond to crevasse-splay and sheetflood deposits. The cross-bedded sandstones within the Moor Grit ('a complex sandstone sheet' of Alexander 1986, p. 302, or 'a valley-fill complex' of Eschard et al. 1991) and the lower Long Nab Member appear to be major channel infills within braided river systems and lateral accretion within meandering channel deposits (Nami \& Leeder 1978; Knox et al. 1991). Nami \& Leeder (1978) proposed an upward change for the Scalby Formation from low sinuosity to high sinuosity channels, accompanied by a reduction in discharge.

Several authors (Alexander 1986, p. 299, 1987, p. 316; Knox et al. 1991, p. 60; Rawson \& Wright 2000, p. 9) have remarked on the abundance and intensity of localized soft-sediment deformation within the Long Nab Member, particularly in the sandstones of the meander belt. These authors commonly link the formation of these structures to water-escape processes ('dewatering structures'). We believe that some of these structures, which exhibit downward drag of beds, may more satisfactorily be explained by 'dinoturbation', the deformation of sediment brought about by the emplacement of a foot. Such an action may have initiated more rapid dewatering of the sediment (section 4.5).

The general lack of coals within the non-marine units of the Ravenscar Group, together with a consideration of the sedimentology, fossil floras, growth ring analysis and presence of charcoal, has led Morgans (1999) and Morgans et al. (1999) to suggest that the region was characterized by climatic seasonality and, during late Bajocian-Bathonian times, by a 'greater aridity' than during the Pliensbachian-mid Bajocian.

\section{TRACK PRESERVATION}

A footprint is made when an animal's foot is impressed into a yielding substrate. It might appear that this impression would effectively be a mould of the foot (foot mould) but, as the resulting footprint usually also embodies evidence both of the motion of the foot and of the physical state of the sediment, such a simple concept is rarely, if ever, applicable. As the substrate yields and deforms, evidence of the passage of the foot will also be transmitted to sediment around and below the footprint through compaction, shearing, dewatering and grain rearrangement. In order for the footprint and associated transmitted structures to be preserved, they must be covered by later sediment, which will cover the surface on which the animal walked and infill the footprint. Lithified prints then become available for study when the rock splits or erodes to disclose aspects of the original structure and its infill. The manner in which this exhumation happens and in which the print becomes displayed has in the literature often been confounded with preservation, though the distinction between the two should be recognized. The exposure or presentational style in which the print is revealed affects the information that can be deduced from it.

The diverse characteristics of the Yorkshire coastal exposures enable the numerous prints to be viewed and studied in a variety of ways. Thus, the prints may be exposed on bedding planes or on vertical surfaces (commonly both) and the heterolithic and homolithic sequences provide varied substrates for print preservation. Although the sporadic intertidal rock platforms of horizontally bedded strata potentially allow extended trackways to be identified, coastal erosion and marine biota normally modify and mask the bedding plane surfaces. The seasonal movement of beach sand and gravel can also affect the amount of rock exposed and the availability of prints. The common occurrence of prints on loose blocks is particularly valuable, though they may be limited in size and ephemeral in nature. The relatively rare inland exposures, mainly in stream sections though also including natural crags and quarries, may yield more long-lasting, but generally more weathered, prints.

In recording prints we were initially much influenced by previous descriptive terminology (e.g. Thulborn 1990; see also below), which emphasized prints seen predominantly in plan view and which distinguished three principal presentational variants. These, and our terminology are:

(a) surface prints: in which the rock splits cleanly along the surface on which the animal moved, to reveal the original footprint-bearing substrate and the infill as part and counterpart (Fig. 5, A3);

(b) underprints: in which the rock splits along a surface intersecting with the print so that part of the original substrate adheres to the infill (Fjg. 5, B4), or part of the infill adheres to the substrate (Fig. 5, B5), or both;

(c) transmitted prints: in which the rock splits along a surface which is entirely below the print and print-bearing surface so that both part and counterpart reveal only transmitted features (Fig. 5, C3, C4).

A fourth variant, overprints, can occur where bedding features within the infilling sedinent are influenced by and, thus, preserve aspects of the footprint (Thulborn 1990, p. 28) and where the rock subsequently splits at such a level and entirely within the infilling material. However, this has been recorded rarely, if ever, in the Yorkshire prints and is not discussed here. It has also become increasingly apparent that many Yorkshire prints are displayed in vertical or oblique sections, which show important aspects of the relationships between the surface print, the transmitted features and the moulding sediment yet do not fit easily into any of the three categories listed above. Furthermore there are a number of prints, which do not fit with, and are more complex than, the very simple preservational paradigm outlined above.

The three groupings and the other preservational and presentational styles are further discussed below. In this and elsewhere in this paper we have followed the following conventions. The terms 'print' and 'track' are used synonymously in a geological sense, in that they refer to the biogenic markings preserved in rocks, irrespective of preservational types. The term 'imprint' is restricted to particular anatomically related aspects of the print (track) morphology such as digit, claw, heel or pad imprint. 'Footprint' is reserved for the impression made in soft sediment by an animal's foot during Iocomotion (but see usage by other authors such as Farlow \& Chapman 1997; Thulborn 1990; Lockley \& Hunt 1995). 'Trackway' is preferred to tracks or trails when referring to two or more consecutive prints made by a particular animal, as the word trackway is so entrenched in vertebrate trace fossil literature (and despite the more suitable term 'track' as defined in the Oxford English Dictionary). Although the terms 'hypichnia'/"epichnia' (Martinsson 1970; Häntzschel 1975) and 'hyporelief'/'epirelief' (Seilacher 1964) are more 


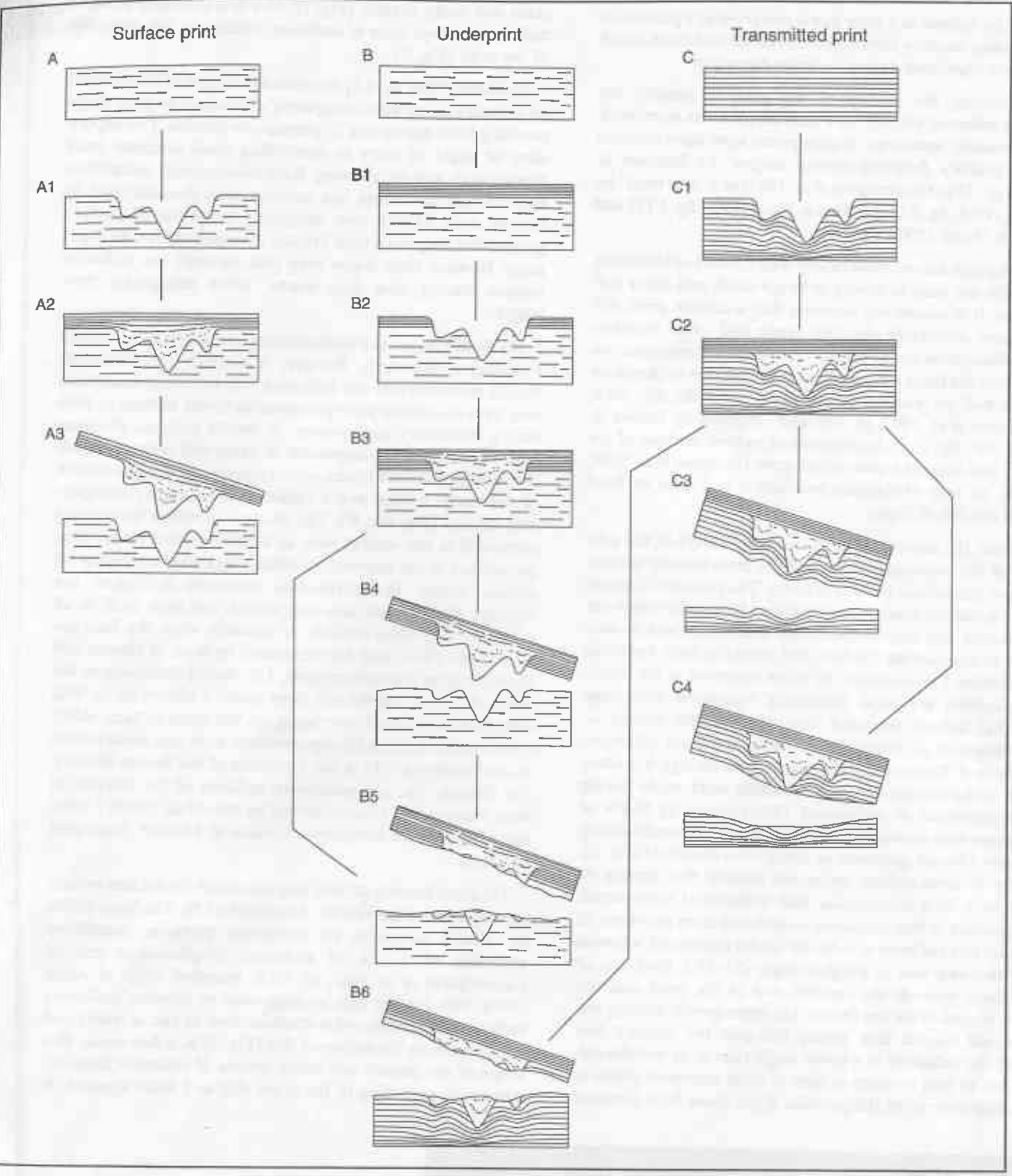

Fig. 5. Schematic diagrams illustrating the mode of formation and preservation of surface prints (A), underprints (B) and transmitted prints (C). Dashed lines represent homogeneous mudrock; horizontal lines represent laminated or thinly bedded sediments. 'Exploded' diagrams at the base of each type show possible preservational variants depending on level of splitting.

normally used to describe the preservation of invertebrate traces, they provide useful additional terminology to indicate the position of the track with reference to the block on which it occurs. Leonardi in Casamiquela et al. (1987) presented a full discussion of the terms and methods used in describing vertebrate tracks.

\subsection{Surface print (track) (Fig. 5, A-A3)}

When Thulborn (1990, fig. 2.1) presented his "simplified model' to explain the preservation of dinosaur tracks, he essentially described a type that we would refer to as a 'surface print (or track)'. Further to the statement above, a surface 
print may be defined as a print that is preserved as a positive or corresponding negative feature on the bedding surface on which the foot was impressed during footprint formation.

By inference, the surface of the print is actually the deformed sediment surface on which the foot was impressed. In the literature, synonyms of such prints have been referred to as a 'primary footprint-bearing surface' by Sarjeant \& Leonardi (p. 53 in Casamiquela et al. 1987) or a 'true track' by Lockley (1991b, fig. 3.1), Lockley \& Hunt (1995, fig. 1.11) and Lockley \& Meyer (2000, fig. 1.9).

Surface prints accord most closely with the sort of footprints that people are used to seeing in beach sands and other soft substrates. It is commonly assumed that a surface print will record most accurately the foot shape and other morphological information on the producer, and indeed examples are known from the fossil record where details of skin impressions are recorded on surface prints (Lockley 1989, fig. 50.1; Casamiquela et al. 1987, pl. 14E and refigured by Tresise \& Sarjeant 1997, fig. 13.9). Impressions of pads on the base of the foot may also suggest a true surface print (Romano et al. 1999. figs 3,4 ), as may phalangeal pads/nodes and claw or hoof marks at the tips of digits.

However, the movement of the foot, the nature of the substrate and the subsequent history of the print-bearing surface also affect the surface print characters. The presence of striae on the sides of the print during footprint formation reflect the mechanics of foot emplacement and withdrawal and so may be used to reconstruct the foot and even the limb dynamics of the maker. The examples of striae observed in the Yorkshire sequence are most commonly associated with large tracks that include sauropod (Brontopodus and Breviparopus; Romano et al. 1999) and probably stegosaur (Deltapodas; Whyte \& Romano 2001) track makers, though it is often difficult to be certain whother the striac were made during foot emplacement or withdrawal. Observations by MAW of emu locomotion showed that similar striac were made during foot entry. On one specimen of Deltapodus brodricki (Fig. 6), two sets of cross-cutting striae are present that appear to record both foot penetration and withdrawal movements. Foot insertion in this specimen, as deduced from the striae, is estimated to have been at c. $40-44^{\circ}$ to the horizontal, whereas foot withdrawal was at a higher angle $\left(53-55^{\circ}\right)$. Both sets of striac slope towards the anterior end of the track and the steeper angled striae cut the earlier, more gently-dipping set. This would suggest that, during this gait, the maker's foot entered the sediment at a lower angle than at its withdrawal. Evidence of foot rotation is seen in deep sauropod prints in which impressions of the anterior digits show both terminal claws and fleshy sheaths (Fig. 7). In a few sauropod prints, a transmitted shear cone of sediment adheres to the underside of the print (Fig. 7).

Thulborn (1990, fig. 4.6) illustrated the effect of foot posture on tridactyl prints when comparing differences in print shape resulting from digitigrade to plantigrade stances. The importunce of angle of entry in controlling fossil dinosaur track morphology and in allowing three-dimensional reconstructions of foot movement has recently been demonstrated by Gatesy et al (1999), who compared footprints of modern ground-dwelling birds with Triassic theropod tracks. As digits move forward their claws may pull through the sediment surface leaving claw drag marks, which exaggerate their length.

Ms Ruth Hughes (an undergraduate recipient of a Nuffield Foundation Research Bursary, University of Sheffield) vividly demonstrated the influence that sediment conditions may have on surface print preservation to the authors in 1993 during laboratory experiments. A model tridactyl dinosaur foot was plunged into substrates of damp and saturated sand; the resulting surface tracks were respectively a sharp replica of the model outline and a vague, shallow, barely recognizable outline (Fig. 8A, B). The chances of either trace being preserved in the natural state as a surface print is very low, on account of the minimal reworking necessary to destroy all surface traces. In intermediate moisture conditions the imprints of claws and claw drag marks, and even parts or all of digits, may close entirely or partially after the foot has moved on. These may be recognized by lines of closure and slight steps on the surface print. The lateral collapsing of the walls of a digit imptint will have marked effects on its final width and may cause overhangs on the print surface. Allen (1997) noticed this in his experimental work and observations on mammalian tracks in the Flandrian of the Severn Estuary, SW Britain. The phenomena of collapse of the margins of digit imprints has been observed by one of us (MAW) while recording surface footprints of emus at Chester Zoological Gardens.

The print-bearing surface may also show the surface expression of transmitted effects. As remarked by Thulborn (1990, pp. 19-20), footprints are commoniy partly or completely encircled by at rim of sediment (displacement rim of Casamiquela of al 1987, pl. VLA; marginal ridge of Allen 1997). This feature can be duplicated in modern sediments such as beach sands and is characterized by radial cracks and micro faults in the sediment rim (Fig. 9) in a few cases. The shape of the feature and actual means of sediment displacement vary according to the grain size and water content. It

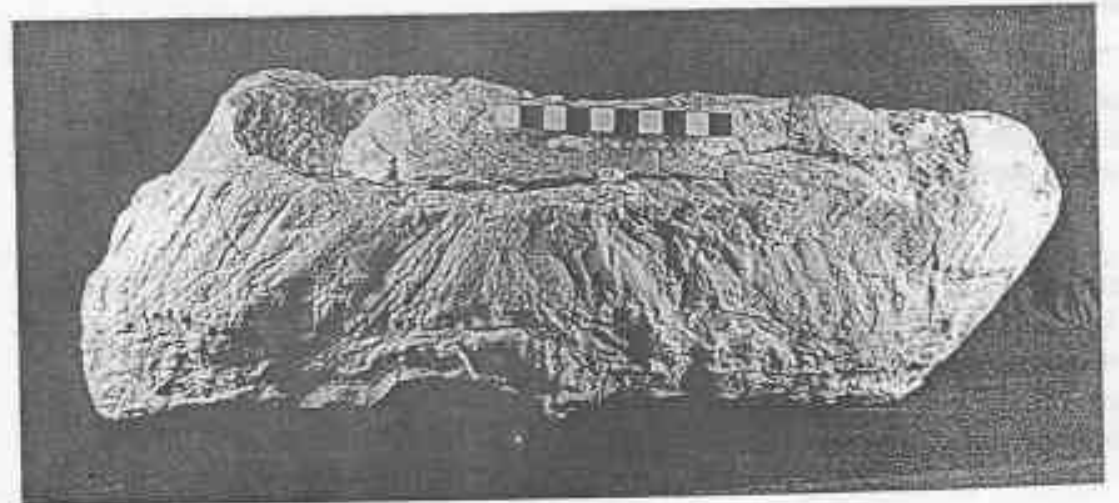

Fig. 6.

Lateral view of print of Deltapodus brodriek showing two sets of cross-cutting striae. Anterior of the print is to the left. Specimen is from the Long Nab Member, Scalby Formation, northem end of Scalby Bay. Scale bar is $10 \mathrm{~cm}$ long. 


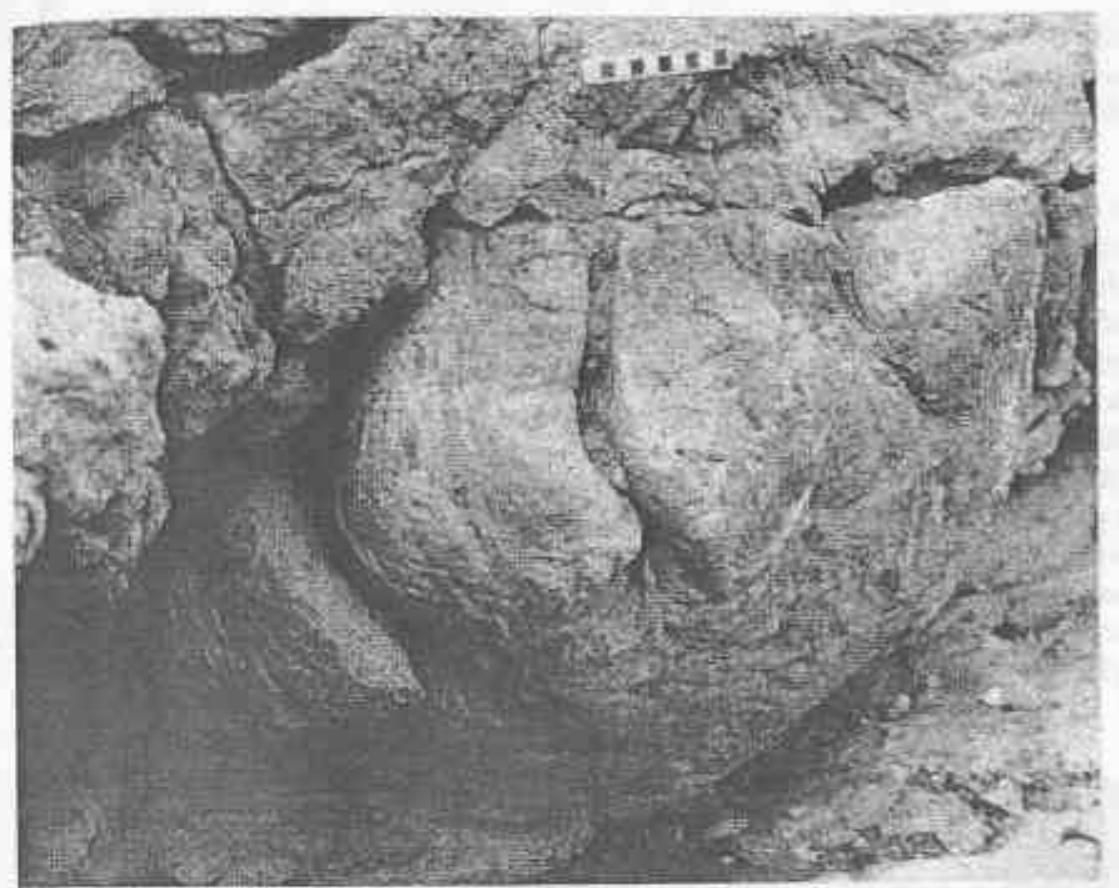

Fig. 7.

Anterolateral view of large sauropod track showing imprints of curved digits with terminal claws and fleshy sheaths. Note the conical bulge of sediment on the underside of the track. Specimen is from the Long Nab Member, Scalby Formation, Comelian Bay. Scale bat is $10 \mathrm{~cm}$ long. would be imagined that sediment rims are rarely preserved, yet such structures have been recorded from the fossil record (Casamiquela et al. 1987, pl. XIX, fig. B; Thulborn \& Wade 1989 , p. 53, fig. 6.3; Thulborn 1990. fig. 2.2). However, in these examples, the preservation of sediment rims as a surface feature is implied rather than proven. Allen (1997) demonstrated that surface marginal ridges (rims) of sediment could be produced experimentally and resulted from subsurface deformation (marginal fold) forming a positive ridge of

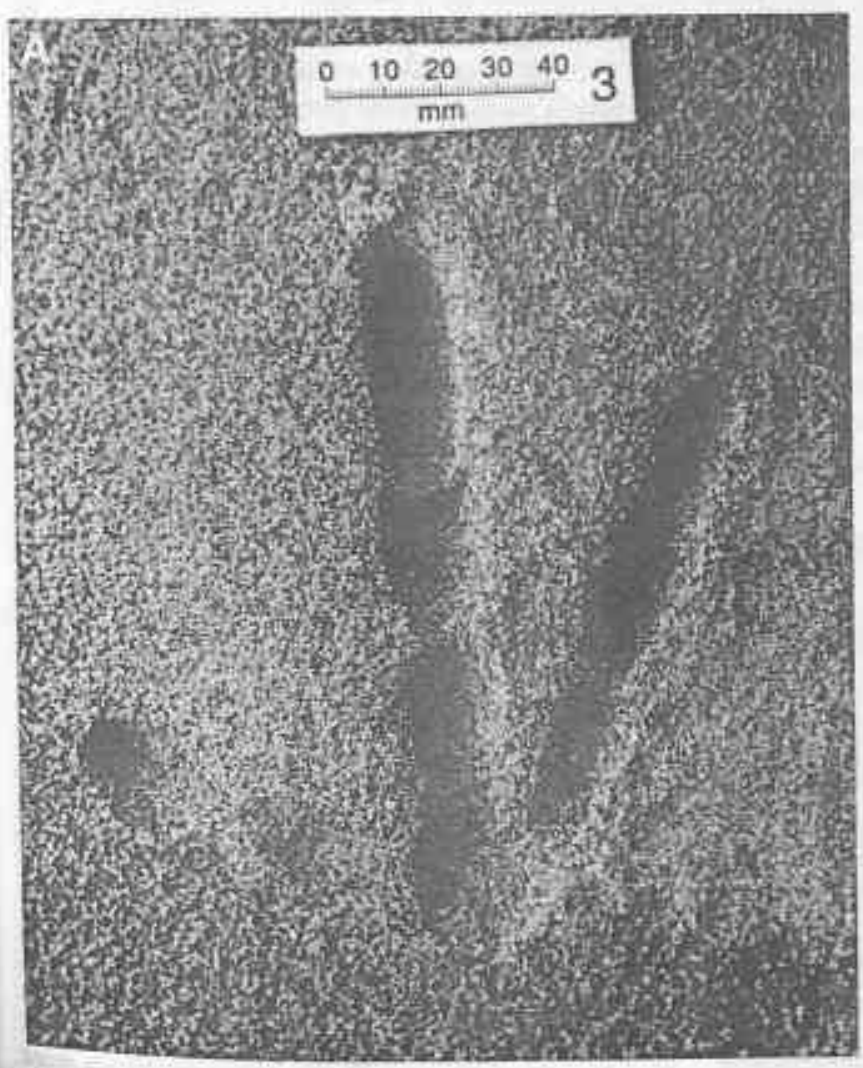

sediment around the print. Allen (1997) also showed that marginal ridges decrease in amplitude downwards; implying that well-developed/high-amplitude marginal ridges are more likely to represent surface (or near-surface) features. If this was the case, the prominent marginal rims around large sauropod tracks (Fig. 10) near the base of the Long Nab Member, south of Scarborough, may be good indicators for these being surface tracks. However, the inwardly dipping margins of the rims indicate a transmitted effect (see below) and these are,

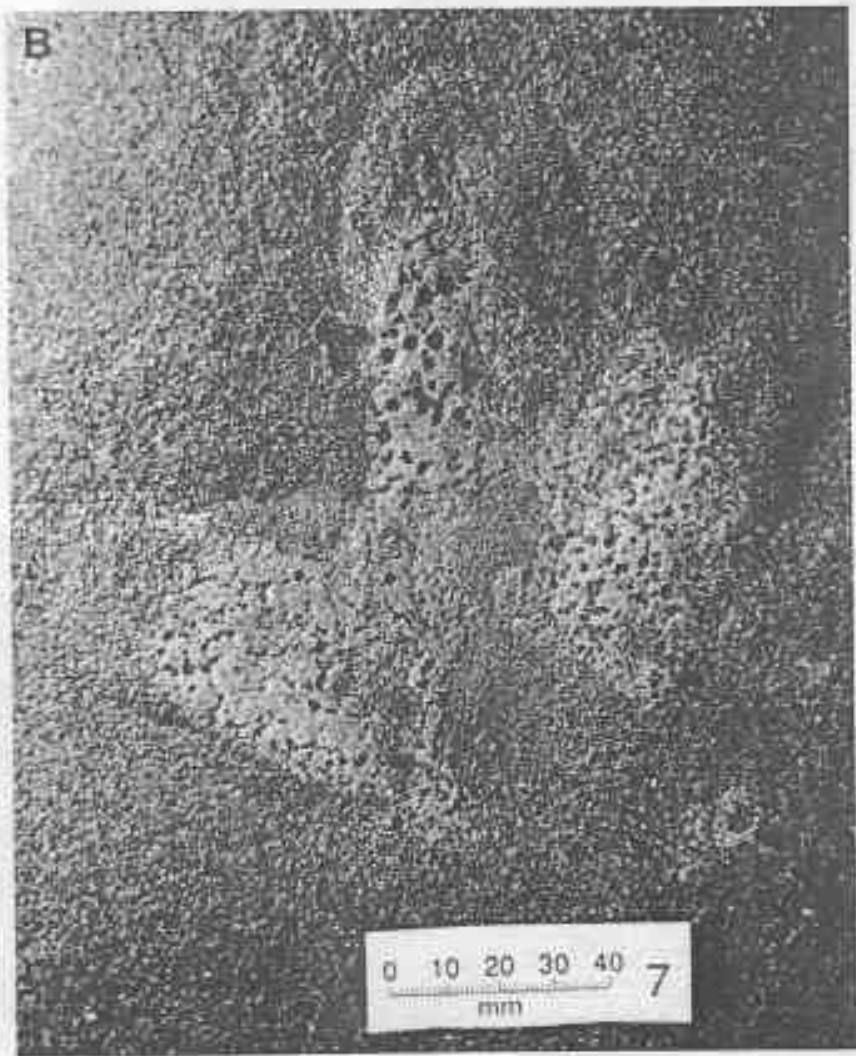

Fig. 8. Experimental surface prints of a model foot impressed into damp (A) and saturated (B) sand. 
thus, more likely to be near-surface prints. Tucker \& Burchette (1977) have described 'pushed-aside' sediment from presumed surface preservations of Triassic dinosaur prints from South Wales.

Although surface prints are perhaps the easiest to understand in terms of formation, they can be difficult to recognize unequivocally. The recognition of print-bearing surfaces is, however, important since it identifies the actual surface on which the footprint was made and, thus, allows accurate reconstructions of the palaeosurfaces on which the animals moved and the palaeoenvironments in which they lived. The initiation of mud cracks radiating out from the track and the presence of rain imprints on the track and adjacent surface may provide confirmatory evidence of the original surface. However, it must be bome in mind that the print and surface may have been modified by other erosive events prior to their being covered by the infilling sediment. Indeed as Allen (1997, p.

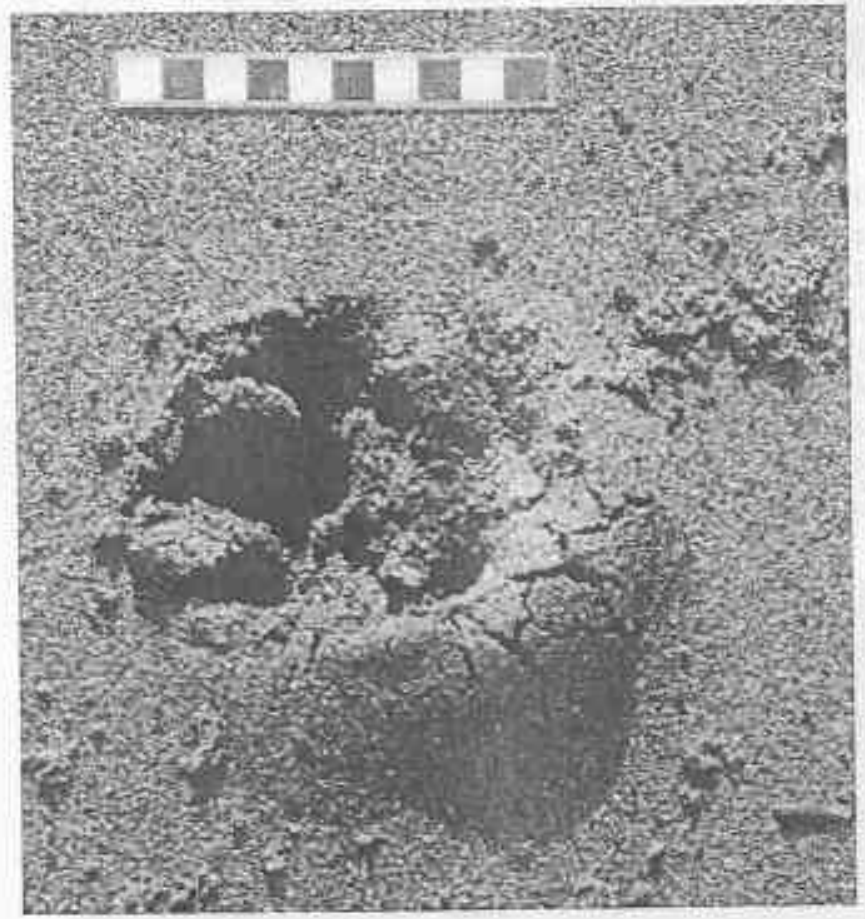

Fig. 9. Footprint of a dog made in damp sand on a beach. Note the raised rim of sand with surface cracking around the posterior margin of the footprint. Scale bar is $10 \mathrm{~cm}$ long.
513) remarked, 'a shaft may on several occasions be partly filled, partly or wholly emptied, and its upper part erosively modified before final burial is achieved'.

\subsection{Underprint (Undertrack) (Fig. 5, B-B5)}

An underprint may be defined as the print that is revealed by a bedding-parallel or sub-parallel fracture, which does not exactly coincide with the print and print-bearing surface but which intersects with it in such a way that part and/or counterpart show both the original substrate and the sediment infill. Underprints are a particularly common and very variable way in which prints may be exposed and many of the Yorkshire dinosaur tracks are displayed as underprints. Because of the common marked lithological contrast between the original substrate and the infill, they can be very striking in appearance though, in some examples, difficult to interpret.

In some underprints, splitting may coincide at least partially with the surface of the print (Fig. 5, B4) so that some aspects of the print morphology, such as pads and nodes and the presence or absence of claws, can still be observed. However, since some parts of the print will still be obscured, measured dimensions may be different from the true dimensions of the surface print. In other cases, the fracture may transect the infill of the print (Fig. 5, B5) and the print surface will be seen only in section. Again, depending on the level of the cross-section, it will be difficult to record reliable dimensional data from such underprints and the amount of morphological information that can be recovered will also be reduced. However, the character of the infill sediment, as discussed below (section 4.4), may be observed. Features of the print-bearing surface will also be obscured, though its position may usually be distinguished to one side of the fracture.

Underprints were described by Thulborn (1990, p. 26) on the basis of prints that had been made and preserved in a laminated sediment. As he noted, splitting along the laminae at successively deeper levels would reveal progressively less of the infill. In extreme cases, where the fracture surface meets only the deeper parts of the print, the underprint may be reduced to showing only a single digit (usually digit III) or even just the tip of that. Where the print has been made in laminated or heterolithic sediment, this may show transmitted effects of the types discussed below (sections $4.3 \& 4.4$ ) and this is a common associate of Yorkshire underprints (Fig. 11). Underprinting can, however, also be observed in homogeneous substrates (Fig. 12).

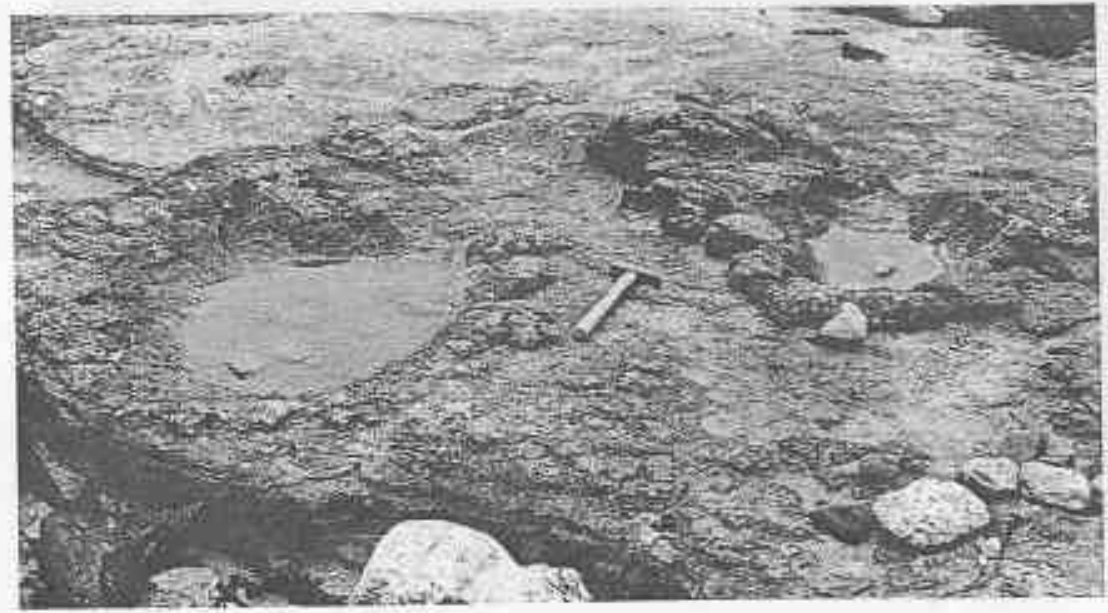

Fig. 10.

Raised rims around large (sauropod) tracks from the Long Nab Member, Scalby Forriation, Comelian Bay. Length of hammer $30 \mathrm{~cm}$. These tracks were first pointed out to the authors by Mr Paul Ensom. 


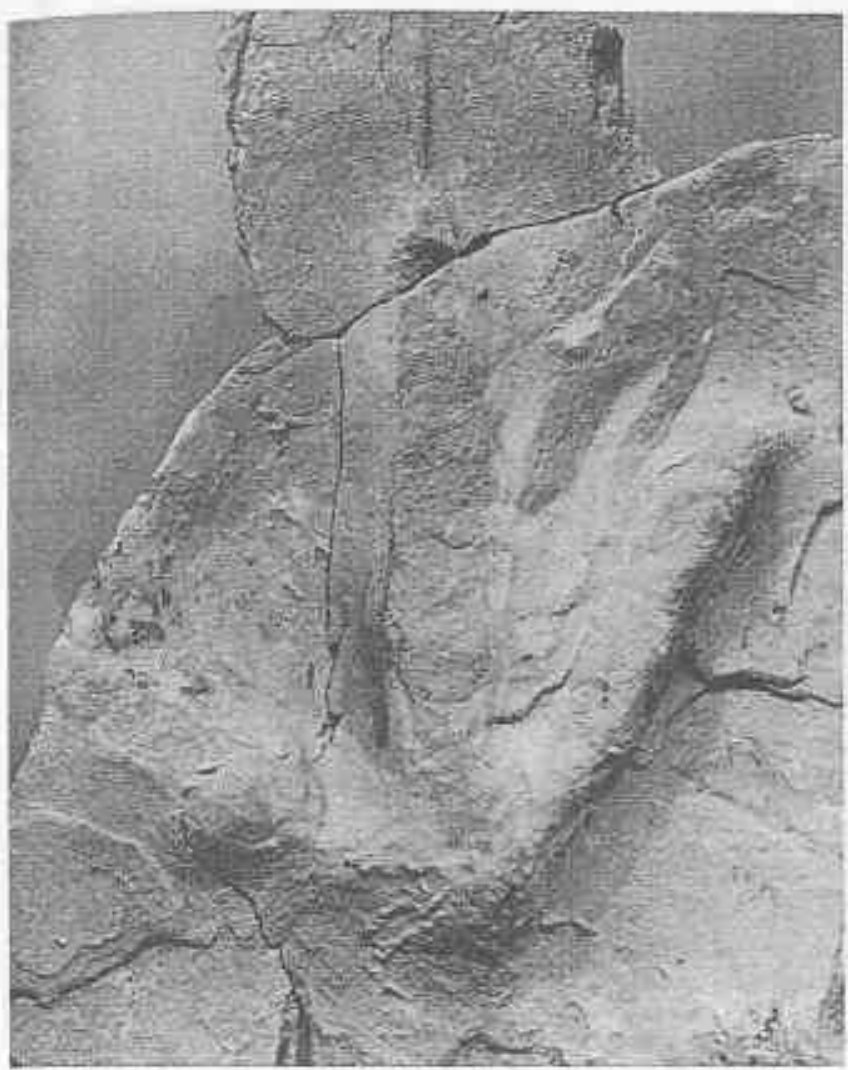

Fig. 11. Tridactyl underprint (morphotype Bix, Fig. 20) showing transmitted effects from the Long Nab Member, Scalby Formation, Black Rocks, Scarborough. Figured by Whyte \& Romano (1981, figs 3, 4) (University of Sheffield specimen number F00766). Print is $14 \mathrm{~cm}$ long.

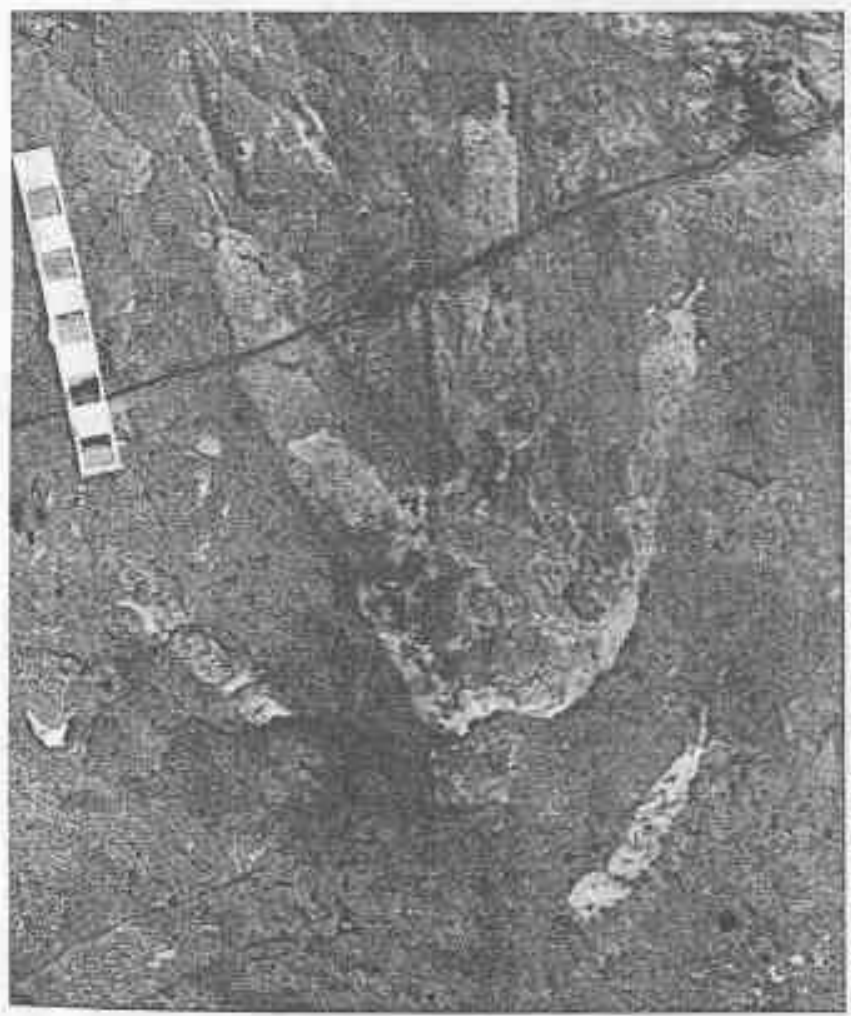

Fig. 12. Tridactyl (morphotype Bvi, Fig. 20) and other incomplete underprints showing claw marks. Gristhorpe Member, Cloughton Formation, Yons Nab. Scale bar is $10 \mathrm{~cm}$.

\subsection{Transmitted print (track) (Fig. 5, C-C5)}

A transmitted print may be defined as a print that displays the distortion of sediments and bedding planes below the surface on which the footprint was impressed (after Ensom 1982, p. 141; 1983, p. 201 and 1995, p.78; Thulborn 1990, p. 27). Synonyms for this preservational type include 'ghost tracks', 'undertracks' or 'subtrace' of Sarjeant (1975), Mossman \& Sarjeant (1983), Lockley (1991b, fig. 3.1), Lockley \& Hunt (1995, fig. 1.11) and Lockley \& Meyer (2000, fig. 1.9).

Transmitted prints are most commonly observed in heterolithic/laminated sediments and the frequency of this character in the non-marine sediments of the Ravenscar Group provides numerous examples of transmitted prints. These are revealed as localized disturbances resulting from soft-sediment deformation and reflecting the outline of a print (Figs 13, 14). Such prints generally become more shallow and ill-defined with depth below the print surface. The character of the transmitted features may be indicative of the state and nature of the substrate (section 4.4).

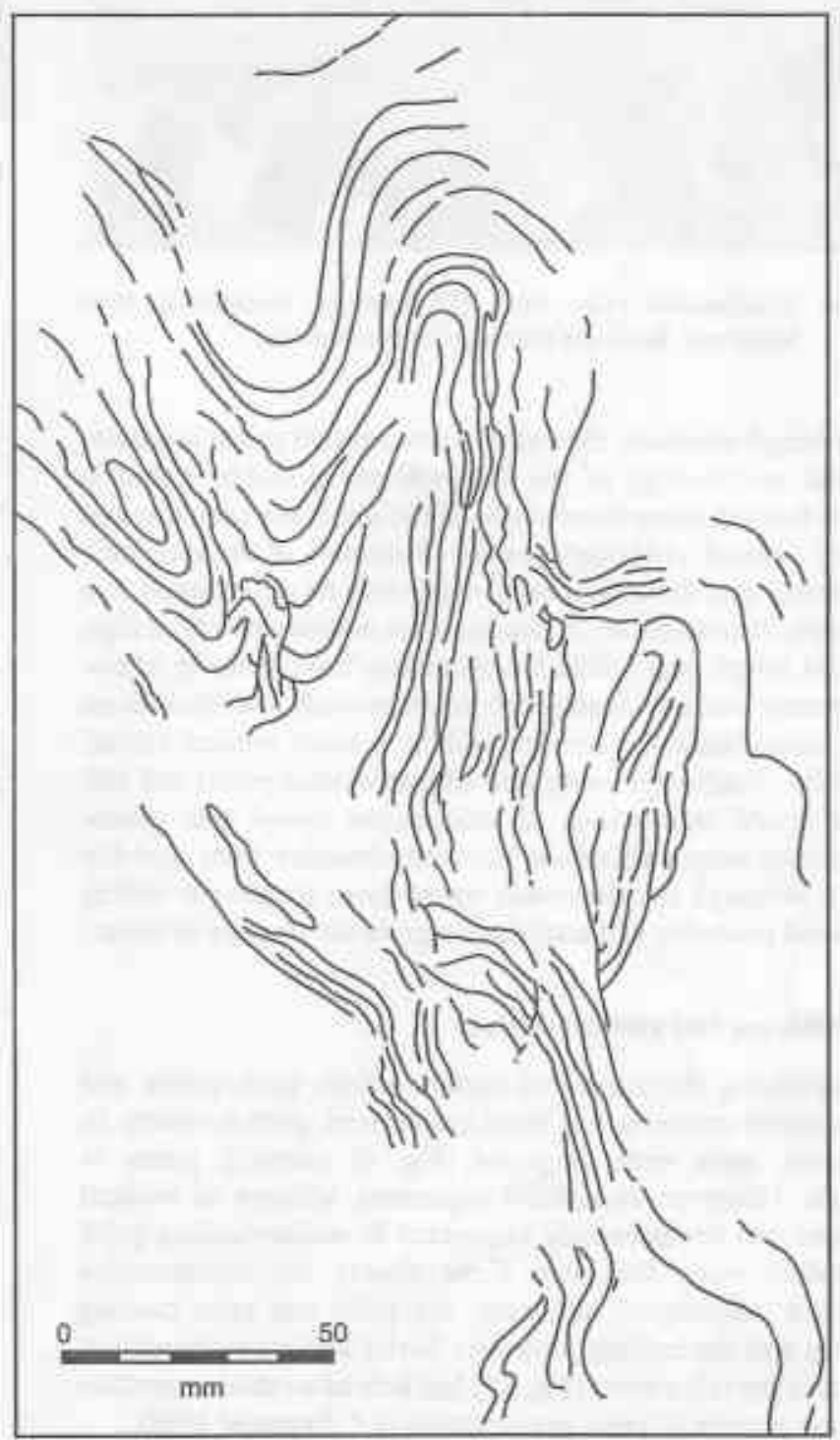

Fig. 13. Tracing of laminae of a transmitted print, showing crude print outline and indications of digit imprints. Saltwick Formation, Long Bight, c. 500 m east of East Pier, Whitby. 


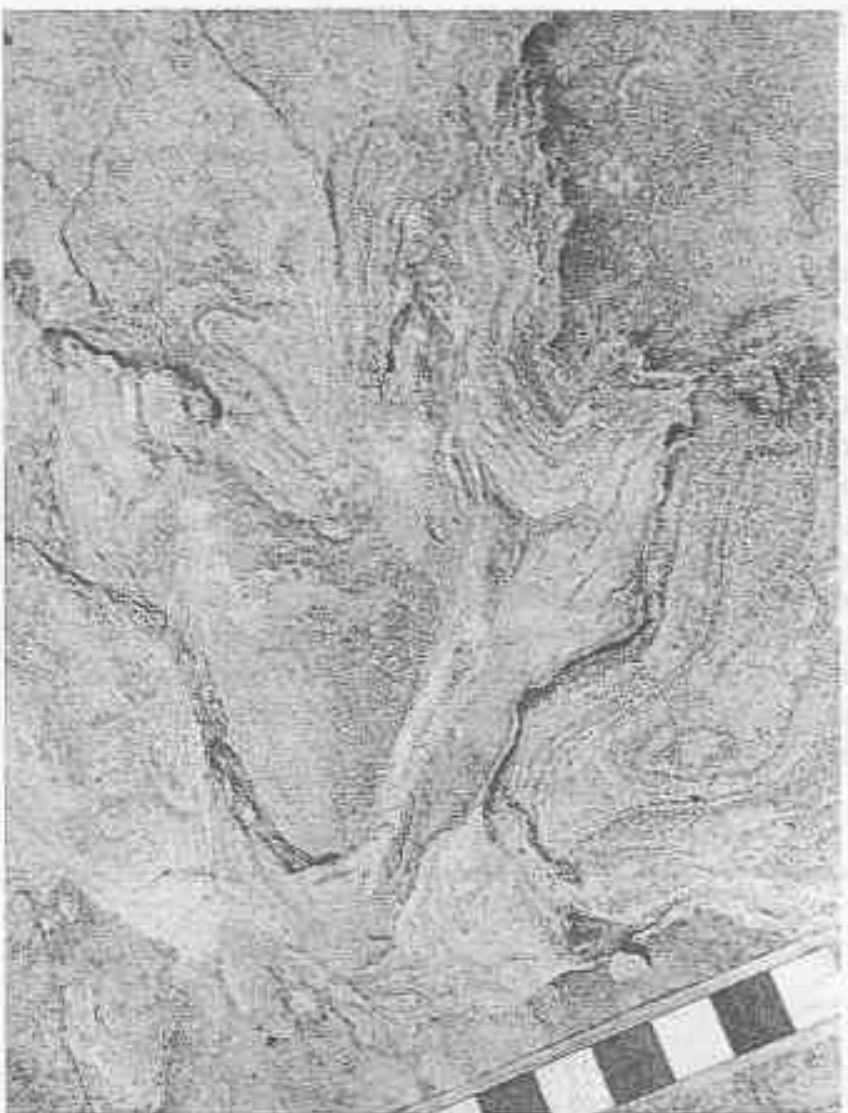

Fig. 14. Transmitted print from the Saltwick Formation, Port Mulgrave. Scale bar is marked in centimetres.

Although common, the value of transmitted prints in assessing the morphology of the foot and the possible maker is rather limited, since the margins of the digits are normally not clearly defined. Although general characters of the foot such as number and divarification of digits may be determined, it is normally impossible to obtain accurate measurements of digit imprint length and width. Despite these limitations in ichnotaxonomic studies, transmitted prints provide information on track abundance, occurrence and, to a more limited extent, diversity. Trackways composed of transmitted prints will still allow crude estimations of locomotion speed and glenoacetabular length (distance between shoulder joint and hip joint), although the inevitably vague print length (or width) obtained probably will introduce significant sources of error.

\subsection{Oblique and vertical sections}

In explaining the nature of surface prints, underprints and transmitted prints, it has been convenient, paradoxically, to illustrate these with diagrams (Fig. 5) showing prints in section. However, in natural exposures, oblique or vertical sections can be extremely important in understanding print formation since they can show clearly the relationships between the original substrate, the print and print-bearing surface and the infilling sediment. Serial vertical sectioning of prints in the laboratory (Fig. 15) has helped to shed important light on aspects of print preservation (c.f. Avanzini 1998).

In oblique and vertical views, the print and print-bearing surface are usually entirely, or almost entirely, seen in section. Although this may obscure certain aspects of the print and in

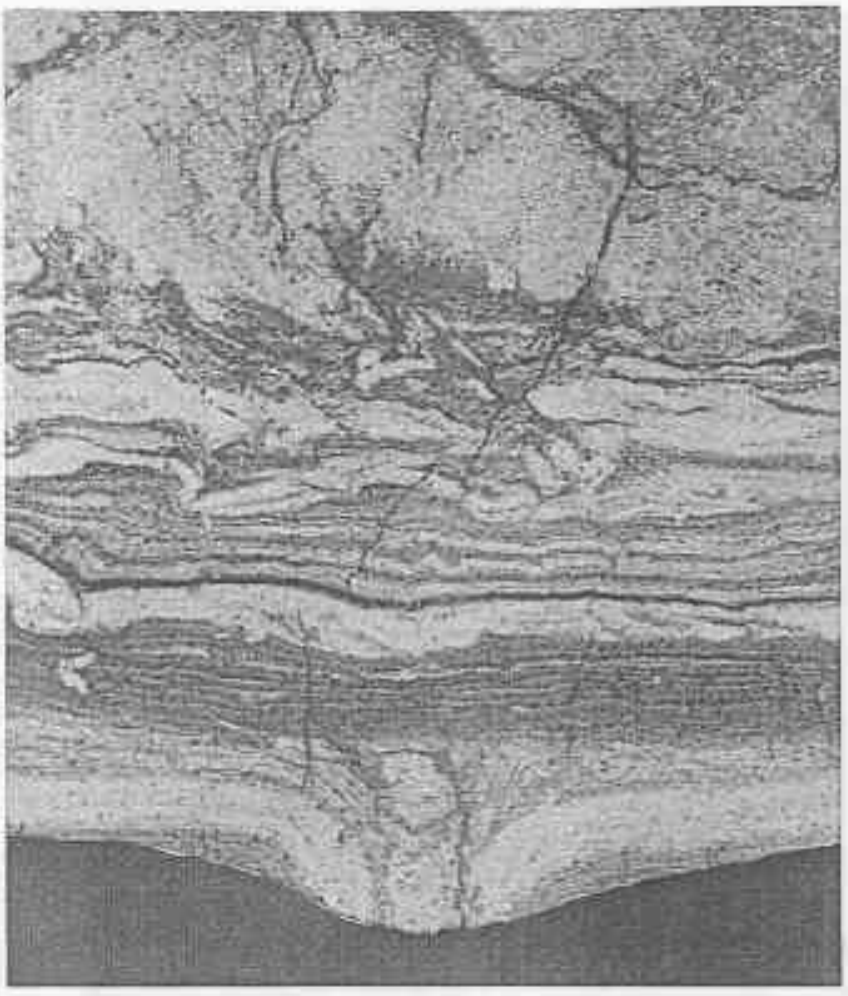

Fig. 15. Cut vertical section of print in rock showing indistinctly bedded infill of middle digit, and transmitted effects. Upper part of section is extensively dinoturbated. Long Nab Member, Scalby Formation, Burniston Bay. Thickness of section is $9.5 \mathrm{~cm}$. (University of Sheffield specimen number F00861).

particular the morphological information that would have a bearing on the possible print maker, it will usually clearly show the relationship between the print and the sediment into which it has been impressed. Where the sediment is heterolithic or laminated it may be possible to distinguish whether the foot has punctured (or ruptured sensu Ensom 1995) through layers or whether it has dragged layers down and deformed/compressed them as the footprint was made. In section, deformed laminae commonly show characteristic downward $\mathrm{U}$ or $\mathrm{V}$ shaped deflections where a digit has depressed and/or disrupted the sedimentary laminae. Sectional views will also allow the extent and character of other transmitted effects, including marginal folds, shears and microfaults to be examined and described. These features will be a function both of the movement of the foot, size of the animal and of the state of the substrate. Allen (1997, p. 483) suggested that it may be necessary to have two nomenclatures in order to describe and differentiate the anatomical (track-specific) characteristics from the sedimentary deformation features caused by the foot emplacement. The condition of the substrate may be determined from the deformational features (plastic and brittle) in the sediment, which thus may provide information on the water content, tenacity and shear strength. Transmitted effects may range from a few centimetres in depth (Fig. 11) (Whyte \& Romano 1981) down to over $0.5 \mathrm{~m}$ below the surface on which the footprint was made (Fig. 16A, B).

The characters of the infilling material may also be instructively displayed in sections. It is commonly assumed that a phase of drying out and hardening is necessary before sediment infill (Thulborn 1990), but in many prints the infill 

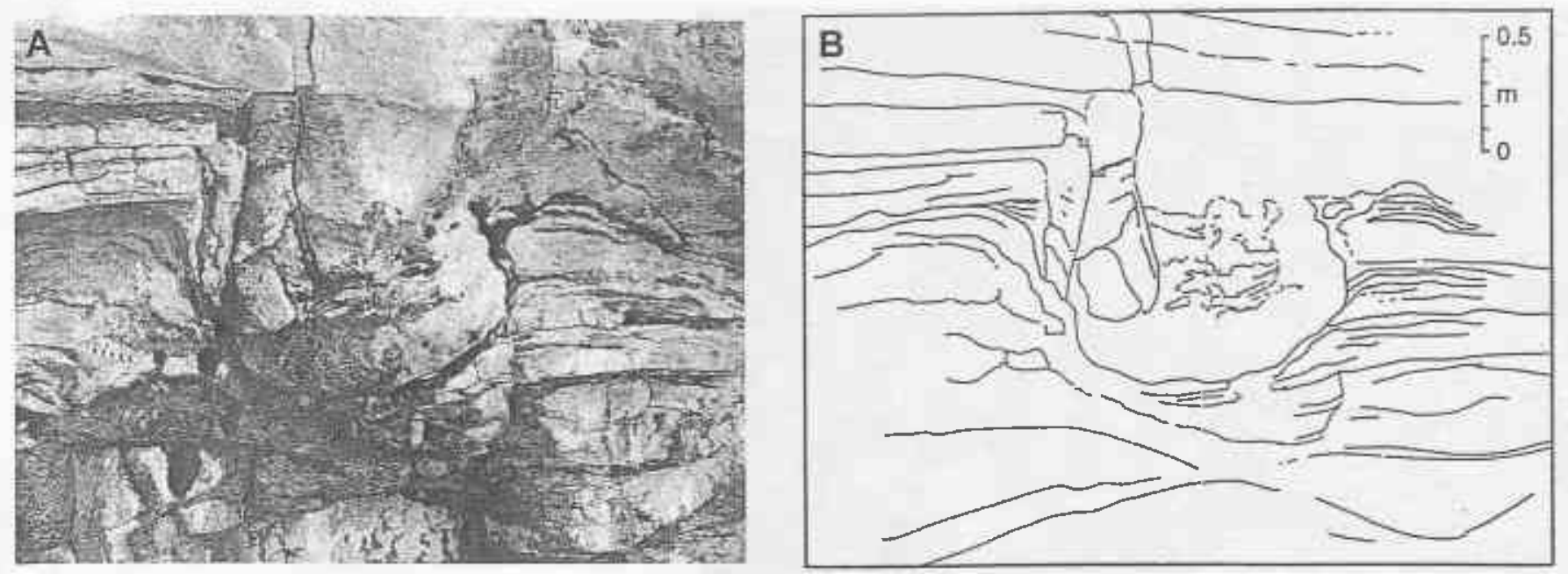

Fig. 16. Field photograph (A), and drawing (B), of a vertical section through a print in situ, showing transmitted effect down to $c$. $0.5 \mathrm{~m}$ below the print-bearing surface. Long Nab Member, Scalby Formation, near Long Nab, north of Burniston Bay. Scale bar in photograph is $10 \mathrm{~cm}$.

appears to have been initiated with an influx of sediment at, or very soon after, foot withdrawal. This may be virtually instantaneous from the slumping of unconsolidated sediment on the sides of the footprint or from the surface, resulting in chaotically bedded structures forming the fill (Fig. 15; also Allen 1997, fig. 24b-d). At other times, the infill appears more homogeneous, yet also points to a rapid fill, since the print may be up to $0.5 \mathrm{~m}$ deep (Fig. 16A, B) and with vertical sides. It is very unlikely that sediment which was saturated enough to be deformed to a depth of $0.5 \mathrm{~m}$ was able to maintain vertical faces for any length of time and indeed, as earlier indicated (section 4.1), collapse of digit walls and partial or complete closure of digit and claw imprints can take place and be detected in unusually narrow and/or irregular infills and by overhangs on the digit walls.

Less rapid infilling may come from sediment being transported over the substrate surface. Theoretically, it should be possible to identify this process since sedimentary structures such as cross-lamination, parallel or low-angle lamination would be present in the infill (e.g. Whyte \& Romano 1995, fig. 3). Intraclasts, if present, may result from suction as the foot was withdrawn, caving in of footprint walls or later erosion of the print-bearing surface (Whyte \& Romano 1995). In a few cases, the infill sediment shows indistinct laminae that reflect the filling of the print, yet are commonly too vague to identify the process. In its crudest form, this may be indicated by indistinct and wavy wisps of carbonaceous laminae. In some cases, the laminae are more complete and may show a distinctive downward curve. This feature is more readily seen in section and may be better observed by vertical serial sectioning through the specimen; the example illustrated (Fig. 15) shows digit III with downward-curved laminae within the infill and transmitted effect adjacent to this digit imprint.

A number of prints seen in section show complex disturbances within which there is evidence of deep digital impressions that have completely closed up (Fig. 17A, B). The resulting surface print is a shallow depression, like those of simulated prints made in saturated sediment (section 4.1; Fig. 8B). Plan views of levels below the surface and intersecting with the digit traces would appear similar to, and could easily be confused with, transmitted prints. Though perhaps closer to underprints, they lack any infill within the digit imprints and there is no simple term for this case. We suggest that a term such as 'collapsed print' might be used for this type of print.

\subsection{Dinoturbation}

We include this type as a separate category, although the sedimentary features present may include some of the types described above. The word was first coined by Dodson $e t$ al. (1980, p. 229), with reference to dinosaur trampling of the substrate and was defined by Lockley $(1991 b$, p. 215) as a 'trampling and disturbance of soils and substrates by dinosaurs'. In the sense of the term used by Dodson et al. (1980), extensively dinoturbated beds are a relatively common feature in the non-marine rocks of the Saltwick, Cloughton and Scalby formations. The typically sandstone beds commonly show planar tops and very uneven, 'loaded' bases (Fig. 18). Thickness of individual units vary considerably and dinoturbated beds interbedded between thick mudstone units in the Long Nab Member, in Gristhorpe Bay, may vary in thickness between $1 \mathrm{~m}$ and $0.5 \mathrm{~m}$ within a very short distance. The internal structure of these beds is also variable and in some instances composite. The two extremes are illustrated by beds that still retain traces of disturbed bedding but also contain underprinted tracks (Fig. 19A, B) with or without digit drag mark, to completely homogenized beds with only rarely recognizable tracks and digit imprints. A few dinoturbated beds have been colonized by plants and the deformation structures are cut by sub-vertical rootlets, indicating colonization after the beds have been trampled. Lockley \& Conrad (1989) introduced a 'Dinoturbation Index' that could be used to denote light, medium and heavy trampling of the substrate surface. This index emphasizes areal distribution rather than depth of disturbance and the limited areal extent of bedding surfaces within the Yorkshire sequences do not permit a detailed assessment of this Dinoturbation Index. However some relatively small exposures indicate that in places the index would certainly qualify as 'heavy'.

The 'localized soft-sediment deformation' within the sandstones of the basal Long Nab Member 'meander belt' (section 

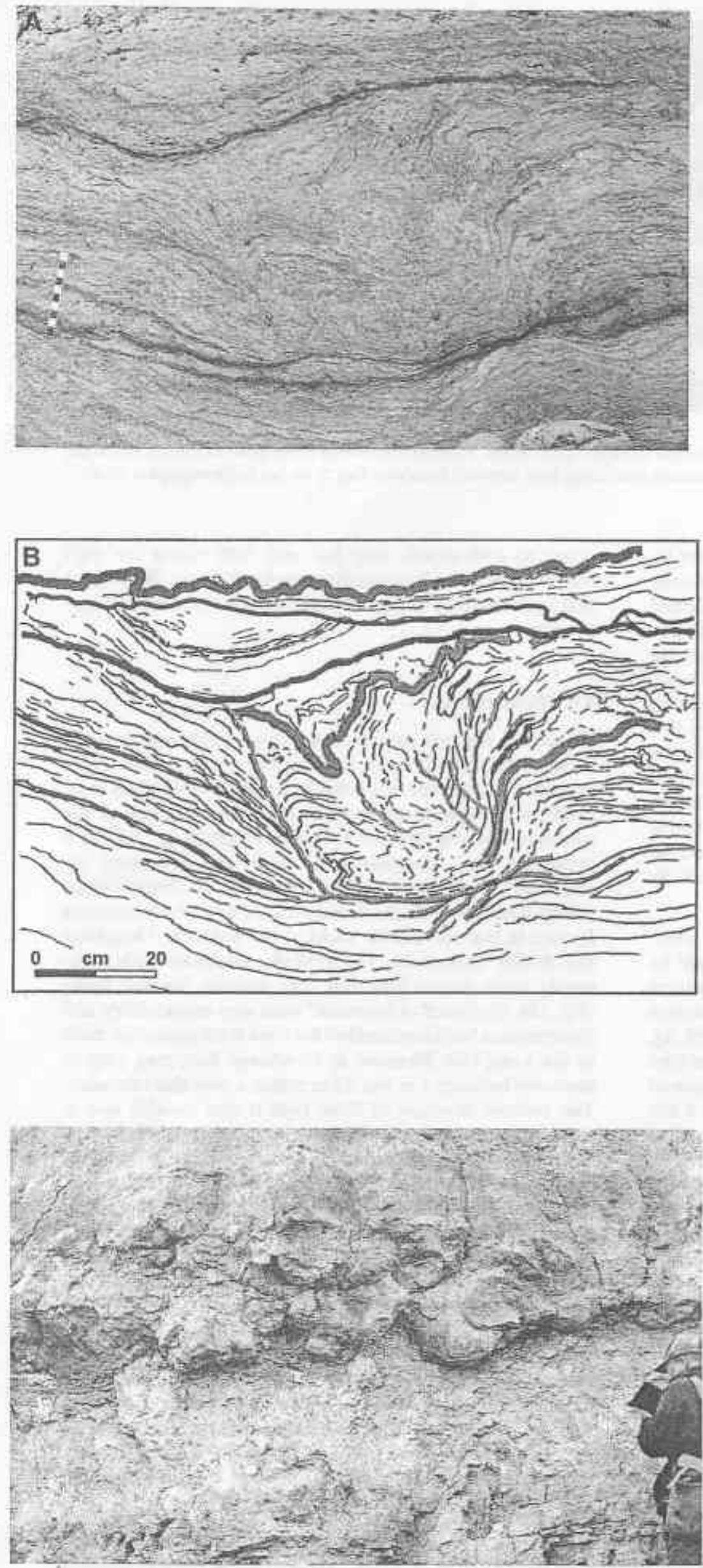

Fig. 17.

Field photograph (A), and drawing (B), of a vertical section through a collapsed print, showing transmitted effect and micro-faulting down to nearly $0.5 \mathrm{~m}$ below the print-bearing surface. Loose block, Saltwick Formation, Long Bight, c. $500 \mathrm{~m}$ east of East Pier, Whitby. Scale bar in photograph is $10 \mathrm{~cm}$.
Fig. 18.

Dinoturbated bed, showing planar tóp and deeply 'loaded' base. Long Nab Member, Scalby Formation, Cornelian Bay. Note person for scale.
3)

se

tu

aI

in

tii

pi

u1

ge

th

$\mathrm{R}$

CC

'b

pl

re

di

ec

m

b)

w.

sa

di

de

th

th

di

th

ni 

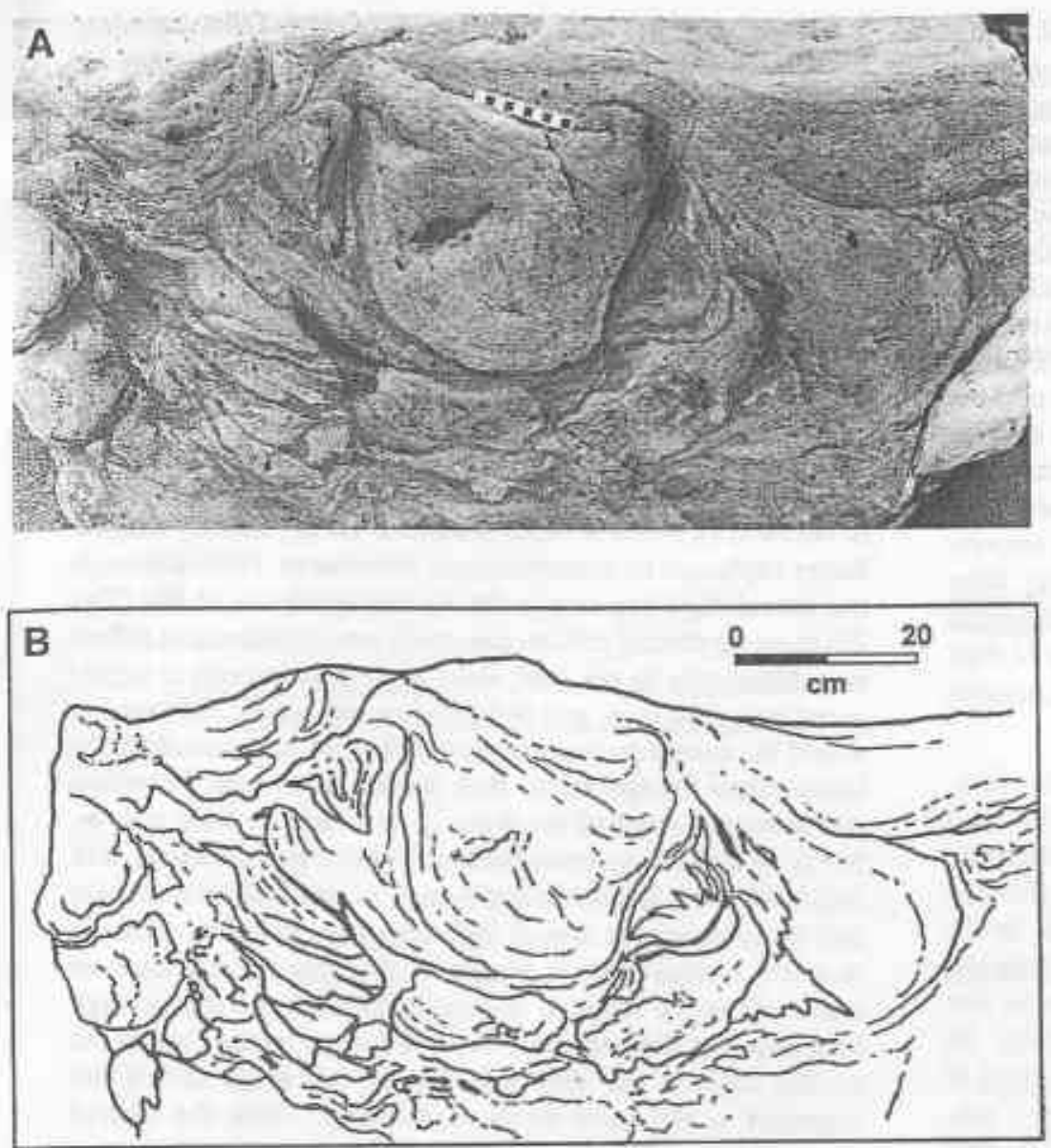

Fig. 19.

Field photograph (A), and drawing (B), of dinoturbated bed with underprinted tracks and disturbed bedding. Loose block, Long Nab Member, Scalby Formation, Gristhorpe Bay. Scale bar in photograph is $10 \mathrm{~cm}$.
3) may result from trampling by dinosaurs in water-saturated sediments. These features are distinct from the types of dinoturbation described above and, though they rarely preserve any details of foot morphology, are important in providing information on dinosaur habitat.

In the slightly broader understanding of the term dinoturbation used by Lockley $(1991 b)$, included are some beds that are particularly characteristic of the Saltwick Formation. In these units, bedding surfaces may be covered with subparallel, elongate grooves or corresponding ridges that record the raking of the substrate by the feet of swimming dinosaurs (Whyte \& Romano 2002). At times the bedding surfaces may be so completely disturbed by raking prints as to be classified as 'heavy' in Lockley's (1991b) Dinoturbation Index. The raking prints are commonly aligned (Whyte \& Romano 2002) and record the unidirectional movement of numerous swimming dinosaurs. This type of dinoturbation contrasts with those equally heavily dinoturbated surfaces that may record the more curvilinear (?random) trackways produced for example by a single animal while drinking or foraging for food. It is worth noting that though the Dinoturbation Index may be the same on both swimming and trampling surfaces the depth of disturbance is usually very small $(<5 \mathrm{~cm})$ in the former case.

Lockley \& Hunt (1995, fig. 7.4) attempted to quantify the degree of trampling, including dinoturbation, throughout the Phanerozoic, but it is difficult to equate our records with the trends they suggest. However, it was noticed that heavily dinoturbated beds are particularly common towards the top of the Saltwick and Scalby formations. The reasons for this are not apparent, but it is interesting to speculate that these periods herald the rise of sea level (and presumably higher water table) prior to the Eller Beck and Scarborough marine incursions respectively. Therefore, the sediments of the coastal plain complex of the Cleveland Basin may have become more saturated with water just prior to inundation by the sea and thus more susceptible to penetration and reworking by the feet of dinosaurs.

\subsection{Trackways}

Since the prints of a trackway have been made by a single animal, they can be of use in helping to understand aspects of print preservation. In particular, anatomical characters may be distinguished from other sources of variation. This may be of importance in ichnotaxonomic studies. Whyte \& Romano (2002), for instance, ascribed differences in print morphology in a pair of prints to substrate differences. Trackways can also indicate whether the maker was moving bipedally or quadrupedally, though in the latter case it must be borne in mind that fore and hind appendages may be impressed into the sediment to different depths. With certain gaits, animals moving quadrupedally may also superimpose or register hind footprints on top of fore footprints with potentially confusing consequences for print morphology and ichnotaxonomy (Whyte \& Romano 2001).

\section{TRACK DIVERSITY}

Firstly, it is important to state clearly the authors' approach to the identification and ultimate naming of fossil tracks and 
trackways. The authors believe that tracks (with their correisponding trackways where possible) should be named when they can be shown to be distinct and consistent morphotypes, irrespective of whether they represent the true foot morphology. This approach to formal taxonomy also includes those trackways that only record the behaviour of the maker (Fig. 20, Group C) and accepts that different morphotypes could conceivably have been made by the same animal, different animals (but perhaps closely related), or even distantly related animals. Whereas it is acknowledged that this procedure may not be acceptable to some vertebrate ichnologists, the authors believe this to be the most easily applicable and least controversial method of ichnotaxonomy. This approach is also consistent with that adopted by workers on invertebrate traces (e.g. Häntzschel 1975; Pickerill 1994). However, it is important to distinguish preservational variants, tracks that have been interpreted as having been modified by sedimentary processes (scouring, dewatering, distortion or closure of digit imprints, etc.) and to exclude these from any formal nomenclature.

For descriptive purposes the tracks from the Middle Jurassic rocks of Yorkshire have been conveniently arranged into three groups (Fig. 20, A, B and C) that are based on morphological and inferred behavioural characteristics. All the outlines are taken from actual prints recorded in the field by the authors. Thus, those tracks that have been made by habitual quadrupeds (Fig. 20, $\mathbf{A i}-\mathbf{v}$ ) are distinguished from those that are the result of locomotion by tridactyl bipeds (Fig. 20, Bi-rvi). The final group (Fig. 20, Ci-vii) include an array of tracks and trackways that are characterized by having individual tracks consisting of parallel to subparallel digit imprints, which are interpreted as having been made by animals during swimming. The majority of the morphotypes in all three groups represent pes (hind foot) prints. Manus (forefoot) prints are known for two morphotypes within Group A (Fig. 20, Aiii and Av) (Romano et al. 1999; Whyte \& Romano 2001), while only one unambiguous manus-pes couple is figured (Av). Morphotype Bxvii is a rather enigmatic trace and may represent either a manus or a pes print.

The morphotypes (Fig. 20) were selected from our database as representing distinct types that may be distinguished from one another by at least two characteristics, such as length and shape of digit imprints, divarification of digit imprints, presence of claw marks and phalangeal/digital pads. As such, they are reasonably well-defined types to which most of the present database and, hopefully, newly collected prints may be assigned with a good level of confidence (see Appendix). So that a workable taxonomy and nomenclature of prints may be established, the validity of these morphotypes in terms of ichnotaxa needs to be resolved. In other words, do the 29 morphotypes recognized represent 29 ichnospecies?

The morphotypes included within Group A (Fig. 20) have already been studied by the authors (Whyte \& Romano 1993 , 1995, 2001; Romano et al 1999) and the reasons given for recognizing five morphotypes will not be repeated here. Thus in this group it is believed that the different morphotypes represent at least three distinct ichnotaxa Brontopodus, Breviparopus and Deltapodis brodricki (see also section 7). Deltapodus brodricki is considered to have been made by a primitive stegosaurian (Whyte \& Romano 2001) and the remaining morphotypes in Group $\mathbf{A}$ are thought to have been produced by sauropods (Romano ef al, 1999).

The morphotypes illustrated in Group B (Fig. 20) are the most common type present in the Cleveland Basin, namely mesaxonie-tridactyl prints, where the middle digit imprint is invariably the longest. Many of the tridactyl prints generally shaw clear asymmetry about the middle digit. At times this may be explained by morphological differences in the lateral digits of the foot of the maker (different lengths, divarification or curvature), while in other examples the asymmetry may be better explained by preservational differences. Thus, although the lateral digit imprints in the figured specimen of Bix (Fig. 20) show significant differences, these are considered to reflect real differences in the foot, since each digit imprint is terminated by a claw print and independent curvature. However, it would be unwise to assume morphological differences in the lateral digits for specimens $\mathbf{B v i i}, \mathbf{B x}-\mathbf{x i v}$, where the distortion and incompleteness of the digits (particularly in Bxii) may be better explained by preservation. Finally, morphotypes Bvii and Bxiii show similar features such as rounded heel margin and quite divergent lateral digit imprints. Yet they differ in that the central digit is longer in the former and narrows anteriorly in the latter. It is conceivable that the central digit impression of Bvii may have been produced by the drag of the middle digit in the sediment, but at this stage this is not regarded as the most likely explanation. Since the figured morphotypes of Bvii and Bxiii differ by more than one character, it is preferential to leave them as separate types for now. To summarize, for the prints in Group B, these studies have not yet clearly distinguished in all cases between true morphotypes that merit ichnospecific status ('track-specific' and 'behavioural types') and preservational variants. Yet it is believed that of the 17 morphotypes figured under this group, at least half may represent distinct ichnotaxa. Some of the tridactyl morphotypes may be closely compared with previously described and figured ichnotaxa. For example, a print from the Saltwick Formation described and identified by Sarjeant $(1970)$ as Satapliasaurus dsocenidzei Gabouniya, 1951, could be assigned to morphotype Biii, whereas types Bv and Bxii show features in common with 'Grallator' and 'Eubrontes' respectively (Lockley \& Hunt 1995, fig. 4.6). The naming of some or all of these morphotypes will be addressed in subsequent papers when the morphotypes have been fully analysed. In the meantime, the Appendix (see also section 7) indicates those morphotypes already assigned to new or existing ichnotaxa.

The tracks and trackways included in Group $\mathbf{C}$ are dominated by morphotypes that reflect a behavioural pattern rather than the anatomical characteristics of the foot. The behavioural pattern is one of swimming and, although this activity may still yield information as to the number of functional digits in the pes (and occasionally manus), the true

Fig. 20. (opposite) Diagrams, taken from actual specimens, showing the range of track morphotypes recognized so far from the non-marine rocks of the Ravenscar Group. The three groups of morphotypes $(\mathbf{A}, \mathbf{B}, \mathbf{C})$ are defined in the text. Brief descriptions of the morphotypes, details of their geographical location, stratigraphical position and taxonomic assignation (where previously determined or suggested here) are given in the Appendix. All types in groups $\mathbf{A}$ and $\mathbf{B}$ are regarded as dinosaurian in origin. In Group $\mathbf{C}$, types $\mathbf{C i v - C v i}$ are assigned to crocodilians and Cvii to chelonians. Note the scale bar for Group $\mathbf{A}$ is different from that common to Group B and Group $\mathbf{C}$. 


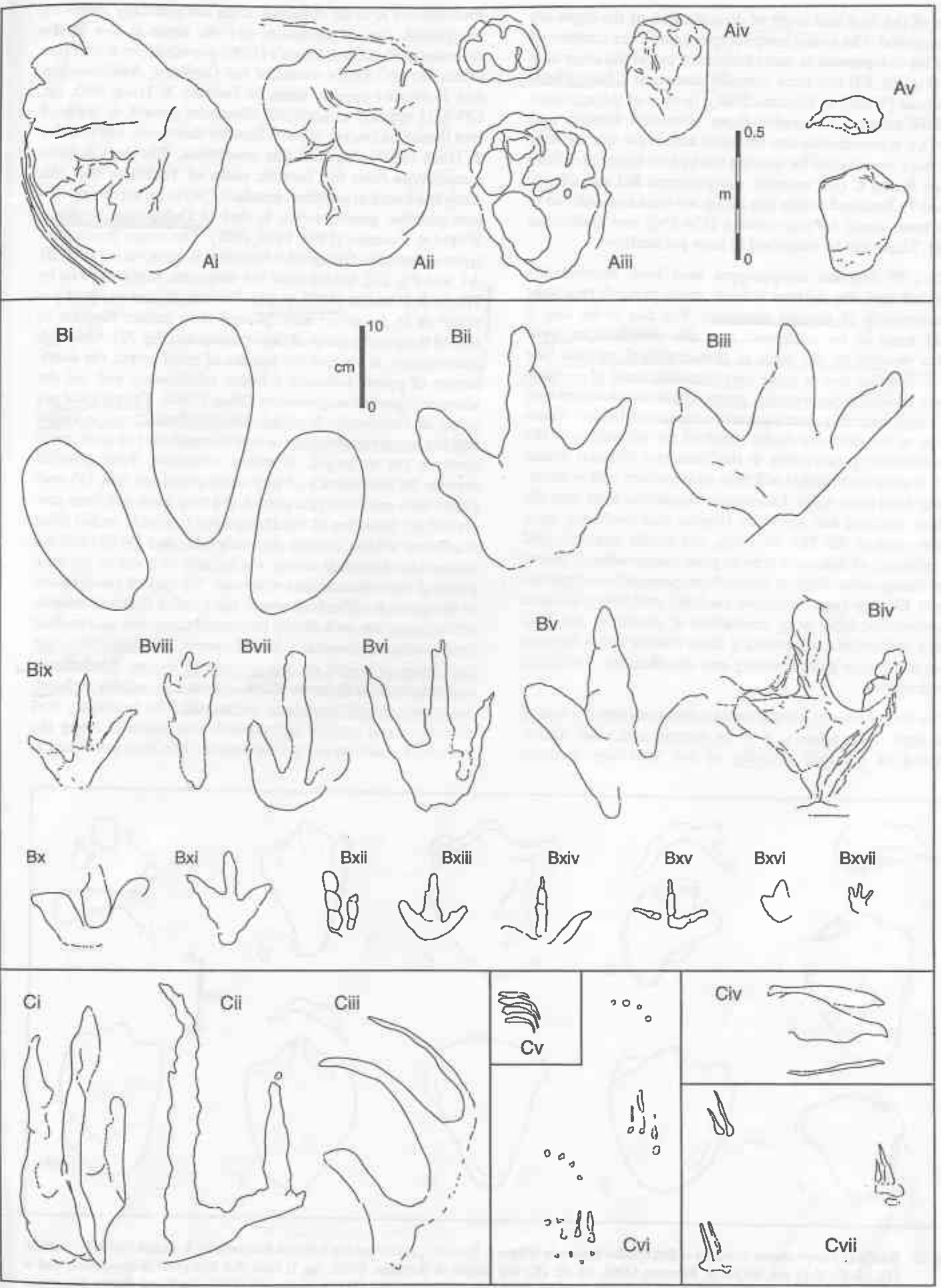


shape of the foot and angle of divarification of the digits are not recorded. The seven morphotypes figured are considered probably to represent as many ichnotaxa, but at this stage only one (Fig. 20, Ci) has been formally named as Characichnos tridactylus (Whyte \& Romano 2002). In view of the approach we have adopted in naming these vertebrate ichnites (see above), it is conceivable that the same animal (or species) may have been responsible for making tracks now included in both groups $\mathbf{B}$ and $\mathbf{C}$ (for example morphotypes $\mathbf{B x i}$ and $\mathbf{C i}$; see section 7). Included within this group are tracks considered to have been made by crocodilians ( $\mathbf{C i v}-\mathbf{C v i}$ ) and chelonians (Cvii). These will be described in later publications.

Thus, 29 different morphotypes have been provisionally identified that, the authors believe, could possibly represent approximately 15 distinct ichnotaxa. For this to be true it would need to be confirmed that the morphotypes were neither erected on the basis of preservational variants (see above) nor that two or more may represent parts of an ontogenetic growth series whereby prints of two morphotypes-may grade imperceptibly over a given size range (see below). These studies so far have not finally resolved the full extent of the importance of preservation in the Yorkshire tridactyl tracks, but it is clear that habitat will play an important role in determining final print types. Laboratory simulation work that the authors initiated for Ms Ruth Hughes and continued by a former student, Dr Phil Manning, has clearly demonstrated the influence of substrate type in print preservation. Current work being undertaken by the authors' postgraduate students Danny Elvidge (morphometric analysis) and Simon Jackson (experimental laboratory simulation of tracks) at the University of Sheffield, is extending these studies and is directed towards a better understanding and classification of tridactyl morphotypes.

The recognition of growth series is also pertinent if a formal ichnologic nomenclature is to be erected and a full understanding of the true diversity of the Yorkshire dinosaur communities is to be obtained. Data are generally sparse on the growth rate of dinosaurs and the same is true in the dinosaur track record. Olsen's (1980) growth series model (see discussion on Olsen's model of the Grallator, Anchisauripus and Eubrontes growth series in Lackley \& Hunt 1995, pp. 120-121) appears to illustrate allometric growth in the hind foot (based on tracks) of some Jurassic theropods, but Lockley \& Hunt (1995) disputed this conclusion. The only definite morphotype from the Jurassic rocks of Yorkshire that this study has found in sufficient numbers (38) to be able to investigate possible growth series, is that of Deltapodus brodricki Whyte \& Romano $(1993,1995,2001)$. The range in morphotypes assigned to Deltapodus brodricki is quite varied (Fig. 20, Av, and Fig. 21), but all show the diagnostic features listed by Whyte \& Romano (1995, p. 24). The length and width of pes prints of $D$. brodricki were plotted on a scatter diagram to record the growth series of this ichnotaxon (Fig. 22). Although inconclusive, in view of the paucity of small prints, the distribution of points indicates a linear relationship and not the allometric growth suggested by Olsen (1980). The rarity of pes prints of Deltapodus brodricki smaller than $20 \mathrm{~cm}$ in length and the apparent absence (or non-recognition) of such prints under $8 \mathrm{~cm}$ in length, is rather enigmatic. Four possible reasons for the absence of very small prints are that: (a) such prints have not been recognized; (b) they have not been preserved; (c) juveniles of the Deltapodus brodricki maker lived in another habitat, outside the study area; and (d) on birth the Deltapodus brodricki maker was already of a size to produce prints of the minimum size observed. The lack of preservation of the prints is difficult to prove, but smaller (lighter) animals will not produce such deeply impressed footprints and so their preservational potential is low. However, tridactyl prints, less than $10 \mathrm{~cm}$ in length, are not uncommon in similar lithofacies and despite their different shape suggest that smaller Deltapodus prints should have been preserved. The possibility that juveniles lived outside the present area exposed along the Yorkshire coast cannot yet be proven. The final possibility is

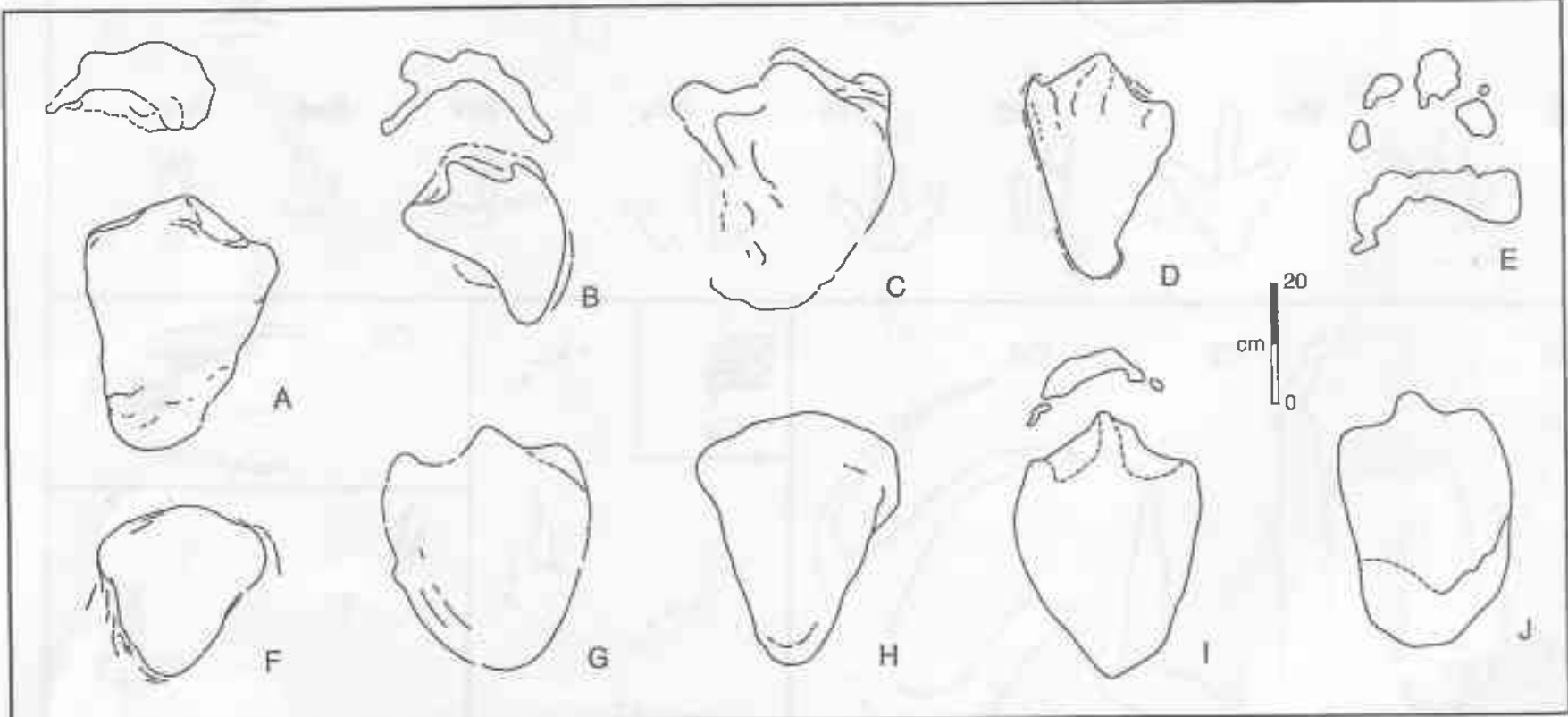

Fig. 21. Range of morphotypes of tracks of Deltapodus brodricki Whyte \& Romano, 1995 from the Saltwick Formation (A-I) and Scalby Formation (J). (A-D, F-I) see Whyte \& Romano (2001, fig. 3). (E) see Whyte \& Romano (2001, fig. 1; note that this print is composite, and is interpreted as a registered track where the manus and pes tracks are superimposed). (J) from just solth of Cromer Point, Scalby Bay; lower part of Long Nab Member, Scalby Formation. 


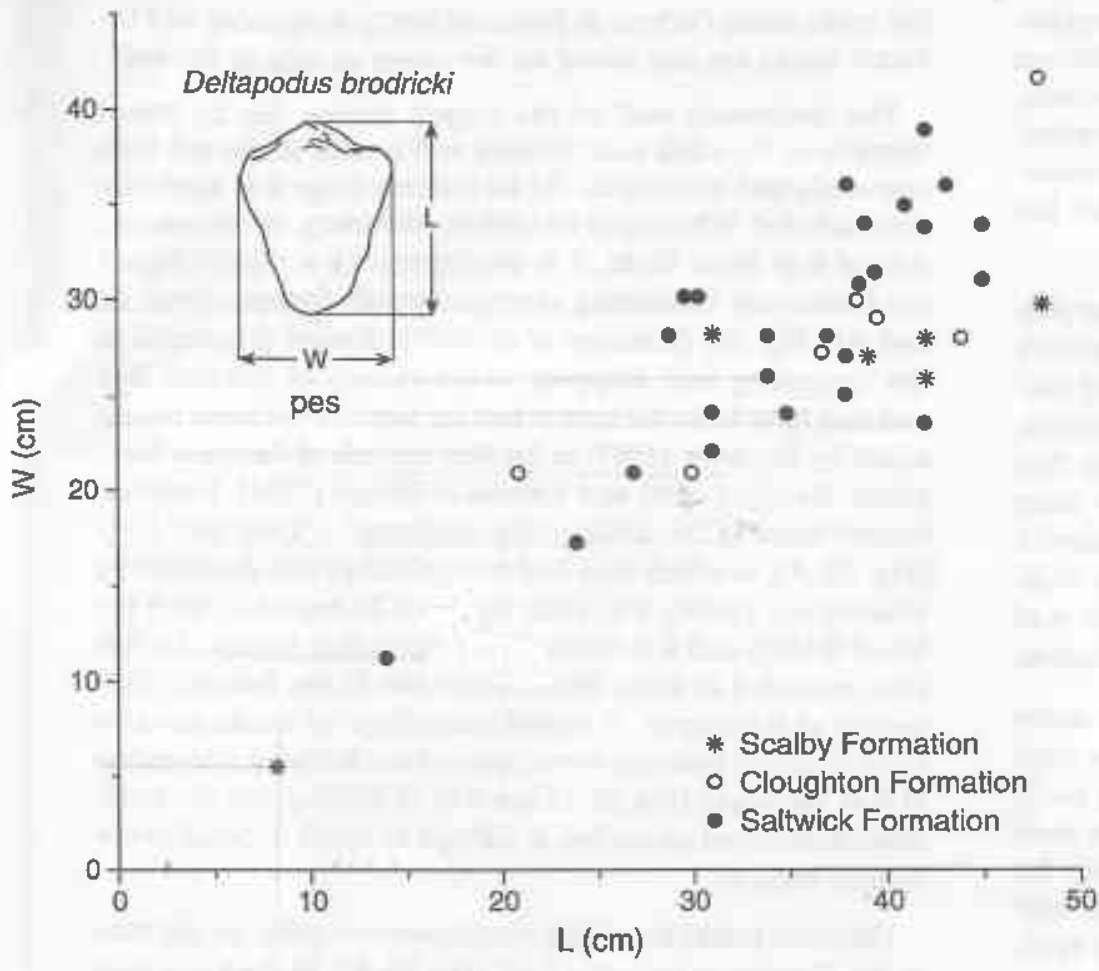

Fig. 22.

Scatter diagram showing plots of pes length against pes width for 38 specimens of Deltapodus brodricki Whyte \& Romano, 1995. Specimens collected from the Saltwick, Cloughton and Scalby formations as indicated. that on birth (either from an egg or by a viviparous mode of reproduction) the juvenile Deltapodus maker was of a size where the pes was approximately this minimum observed length. If this was the case then the longest (c. $48 \mathrm{~cm}$ ) recorded Deltapodus print was six times as long as that of the hatched juvenile. If the growth series of Olsen (1980) is correct (Lockley \& Hunt 1995, fig. 4.6), then the length of an adult bipedal tridactyl pes track may be over 25 times as long as that of a juvenile. This is a considerably larger ratio than that presently shown for Deltapodus and suggests that we would expect to find smaller pes prints of the Yorkshire ichnotaxon. Comparisons with other dinosaurs (Chure et al. 1994; Carpenter 1999) also indicate that juveniles should have existed that were of a size potentially able to produce considerably smaller prints than the single observed $8 \mathrm{~cm}$ long example. Thus, it would have been expected that more and smaller Deltapodus prints would have been found if the young had lived in the same area and habitat as the adults. It is noteworthy that Deltapodus prints are relatively rare until they reach a length of c. $28 \mathrm{~cm}$ (Fig. 22). Above this length, they are much more abundant. This may indicate either that the preservational potential significantly improves after footprints (and associated increase in body weight) reach a critical size, or that mature juveniles are joining the adult populations living on the coastal plain. At present, this question cannot be conclusively resolved.

A potentially important aspect of track diversity concerns the possibility of sexual dimorphism. Comparisons with extant vertebrates suggest that it is probable that some dinosaurs exhibited sexual dimorphism (Sampson 1997, p. 389). Such dimorphism may have resulted either in characteristic ornaments, for defence or weaponry or sexual display, as suggested for the horn-faced dinosaurs (Dodson 1996, p. 23), or may have expressed itself in body size and shape. If this was the case, then it might be expected to show up in the ichnologic record where the print of one sex is smaller and possibly more gracile than the print of the other dimorph. Some authors (see Sampson 1997, p. 390) have suggested that in dinosaurs the larger, more robust, skeletal form represents the female but, when Tresise (1996) recognized that Chirotherium tracks commonly fell into two categories, slender and stout, he tentatively attributed the former to the female and the latter to the male. As Lockley \& Meyer (2000, p. 59) stated, the subject remains controversial. While the authors are not in any position to be able to suggest possible sexually dimorphic variants in the track record from Yorkshire, the possibility that among the morphotypes recognized (Fig. 20) there may exist at least one sexual dimorph should not be dismissed.

A final consideration of dinosaur track diversity from the rocks of the Cleveland Basin concems the apparent absence of tail drag marks. There are no convincing records of grooves associated with isolated tracks or trackways that may be interpreted as disturbances resulting from the contact of the tail of a dinosaur with the sediment surface. Tail marks were briefly discussed by Thulborn (1990, p. 89) and Lockley (1991b), who pointed out the rarity of such traces. The reasons for their rarity, or absence, may be due either to animals generally lifting their tails clear of the ground, or that any tail contact with the substrate was rarely sufficient to disturb more than the surface of the sediment and thus any trace would have a low preservation potential.

\section{TRACK DISTRIBUTION AND ABUNDANCE}

Vertebrate tracks are arguably the most characteristic feature of the Ravenscar Group. Far from being confined to a few restricted horizons, such as the Burniston 'footprint bed', they are found within the 'non-marine' lithostratigraphical units at almost every level where there are suitable lithological contrasts. Indeed bedding surfaces which lack any evidence of vertebrate activity are in their own way noteworthy. Tracks 
even occur within parts of some 'marine' units, thus emphasizing the subtle and intimate inter-fingering of different facies. However, because of the restrictions of the exposures, the facies variations and the problems of track preservation, the distribution of vertebrate traces is difficult both to quantify and to summarize despite the large database that has already been accumulated.

Establishing the distribution of the various track morphotypes (Fig. 20) within the Ravenscar Group is almost entirely dependent on the detailed sedimentological logging of successions and of their in situ tracks. In favourable situations, tracks on loose blocks may be traced back to source beds, thus extending the data set. The process is illustrated by three examples (Fig. 23) taken from the lower part of the Saltwick Formation and from two parts of the Scalby Formation. Sedimentological interpretation of the logs and determination of the facies and habitat will be addressed in a later publication.

The lower part of the Saltwick Formation at Whitby shows dinosaur tracks occurring in three contrasting sandstone units (Fig. 23, A). Only the lowest of these beds is relatively easily accessible in the cliff and in all three units, prints are most obvious in fallen or slumped blocks. The lowest bed, for convenience referred to informally as the "heterolithic bed" (Fig. 23, A), is a laminated unit of finely interbedded sandstone, siltstone and mudstone penetrated by vertical rootlet structures. This unit has indeterminate sauropod prints (Group A morphotypes) at its base (Romano ef al. 1999). These are currently the oldest, stratigraphically well-located, prints in the Ravenscar Group. Within the 'heterolithic bed' and particularly towards its top there are disturbed layers which, when seen in plan view, reveal the presence of both Dellapodus (Fig. 20, Av) and tridactyl transmitted and underprints (Figs 23, 24).

Above the 'heterolithic bed', the second unit is a crossbedded medium-grained sandstone (Whyte \& Romano 1993, 1994) with Deltapodus, indeterminate tridactyl and swimming prints only on its base (Figs 23,24). The unit is informally referred to as the 'Deltapodus sandstone' (Fig. 23, A). The prints of this unit include the type material of Deltapodus brodricki (Whyte \& Romano 1993, 1994, 2001) and are impressed into silty mudstones containing the fresh-water bivalye Unio, which is reputed to be the earliest occurrence of unionaceans in Europe (Kendall \& Wroot 1924). Sideritized mud clasts in the base of the sandstone show that some erosive modification of the print-bearing surface may have taken place.

The third sandstone unit, the 'swimming bed' (Fig. 23, A), is a composite unit composed of a number of ripple crossbedded, fine-grained sandstone layers with dinoturbated interfaces and a few thin mudstone partings. The basal sand layer has infilled a sauropod trackway (morphotype Aiv, Fig. 20; Romano et al. 1999) and above this there are internal surfaces with a complex of surface, transmitted and underprinted tracks (Whyte \& Romano 2002). This ichnoassemblage of swimming and tridactyl morphotypes reveals a more complex environmental history for the unit than can be deduced from the rocks alone (Whyte \& Romano 2002). Swimming and tridactyl tracks are also found on the upper surface of the unit.

The 'swimming bed' of the logged section can be traced laterally in the cliffs near Whitby and is seen to die out both eastwards and westwards. At its western edge it is markedly dinoturbated. Whereas at its eastern extremity, on the eastern side of Rail Hole Bight, it is overlapped by a slightly higher sandstone unit containing sauropod prints (morphotypes Ai and Aii, Fig. 20) (Romano et al 1999). Similar lithologies to the 'swimming bed' reappear in the vicinity of Saltwick Bay and may have been the source bed for some of the loose blocks noted by Brodrick (1907) in his first records of dinosaur footprints. Kendal (1908) and Kendal \& Wroot (1924), however, related them to the 'Deltapodus sandstone' - 'Unio bed' level (Fig. 23, A), in which they had recognized prints. As noted by Hemingway (1974), the 'Unio bed' can be traced up to $4 \mathrm{~km}$ SE of Whitby and it is interesting to note that Deltapodus has been recorded in loose blocks from low in the Saltwick Formation at Ravenscar. A varied assemblage of tracks has also been recorded from the lowest part of the Saltwick Formation at Port MuIgrave (Fig. 2), $12 \mathrm{~km} \mathrm{NW}$ of Whitby, but the sandstone dominated succession is difficult to relate in detail to the Whitby section.

Dinosaur tracks have long been known to occur on the base of the 'Burniston footprint bed' (Fig. 23, B), in the Long Nab Member of the Scalby Formation (Hargreaves 1913; Black $e t$ al. 1934; Ivens \& Watson 1994). In the past, fallen blocks from this bed were relatively common on the shore but have now been destroyed or removed by collectors. These prints, which include several types of tridactyl prints (e.g. Fig. 20, Bix, Bv), appear to be underprinting from different levels within the basal bed, which has a complex internal structure with ripple cross-laminated units. Above this bed, prints occur in at least two other levels within this sandstone (Fig. 23, B). The lower of these is a thin dinoturbated layer with underprinted digits from indeterminate clawed tridactyl prints. The upper level also has tridactyl prints (type Bix, Fig. 20) preserved within a sideritized sandstone and thus showing both underprint and transmitted features in a relatively uncompacted state.

At the steps (Crook Ness), in the middle of Burniston Bay, the 'Burniston footprint bed' is separated from underlying current-bedded sandstones by $6 \mathrm{~m}$ of mudstones and siltstones, within which two thin dark carbonaceous beds form useful marker beds. Definite tracks have not been detected in these mudrocks though some large disturbances might be due to dinoturbation. About $40 \mathrm{~m}$ north of the steps a lenticular sandstone appears c. $1 \mathrm{~m}$ below the 'Burniston footprint bed'. This sandstone, which is affected by shrinkage cracks, contains indeterminate tridactyl prints that underprint to its base. The 'Bumiston footprint bed' can be traced both northwards and southwards in Burniston Bay. However, detailed logging shows that to the south it pinches out and is replaced at slightly different levels by other similar sandstones which also contain tridactyl prints. Work is still going on to relate track-bearing surfaces within these beds. Farther south, between Cromer Point [030 928] and Scalby Ness [037 911], the succession has been cut by a number of channels (Black et al. 1934; Nami \&

Fig. 23. (opposite) Stratigraphical logs of three selected sequences within the Ravenscar Group of the Cleveland Basin, showing print morphotypes and horizons. A - basal part of the Saltwick Formation (composite section); Rail Hole Bight, $700 \mathrm{~m}$ east of Whitby Pier. B - middle part of Long Nab Member (basal 'Level Bedded Series'), Scalby Formation; Burniston Bay, immediately north of Crook Ness. C - uppermost part of Long Nab Member, Scalby Formation; Gristhorpe Bay. 


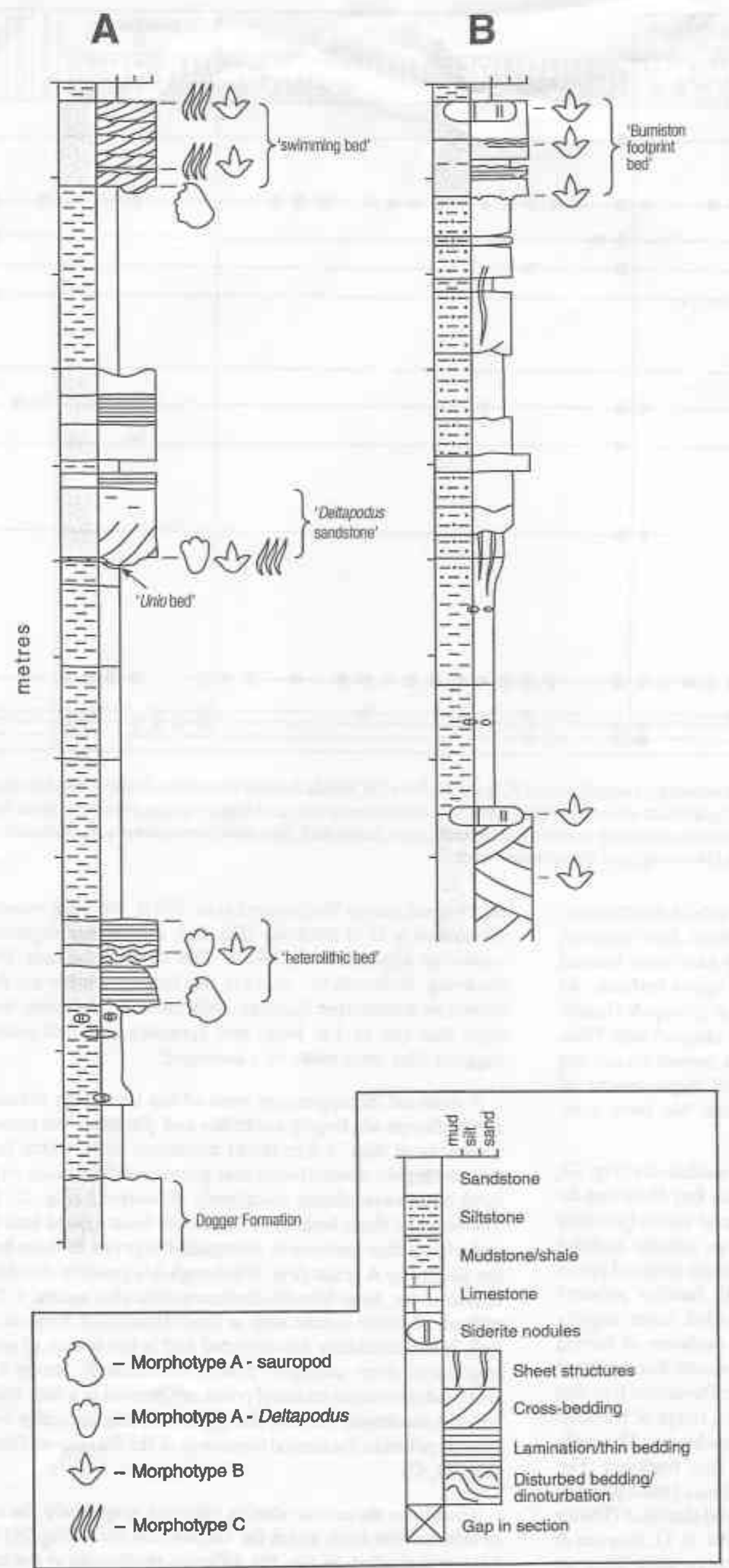

C

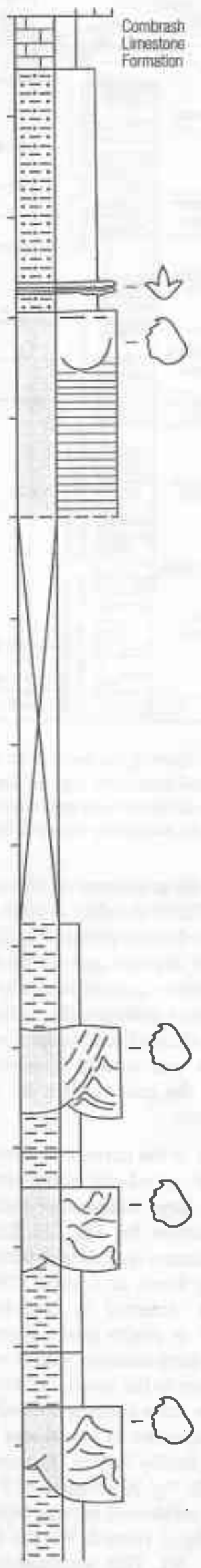




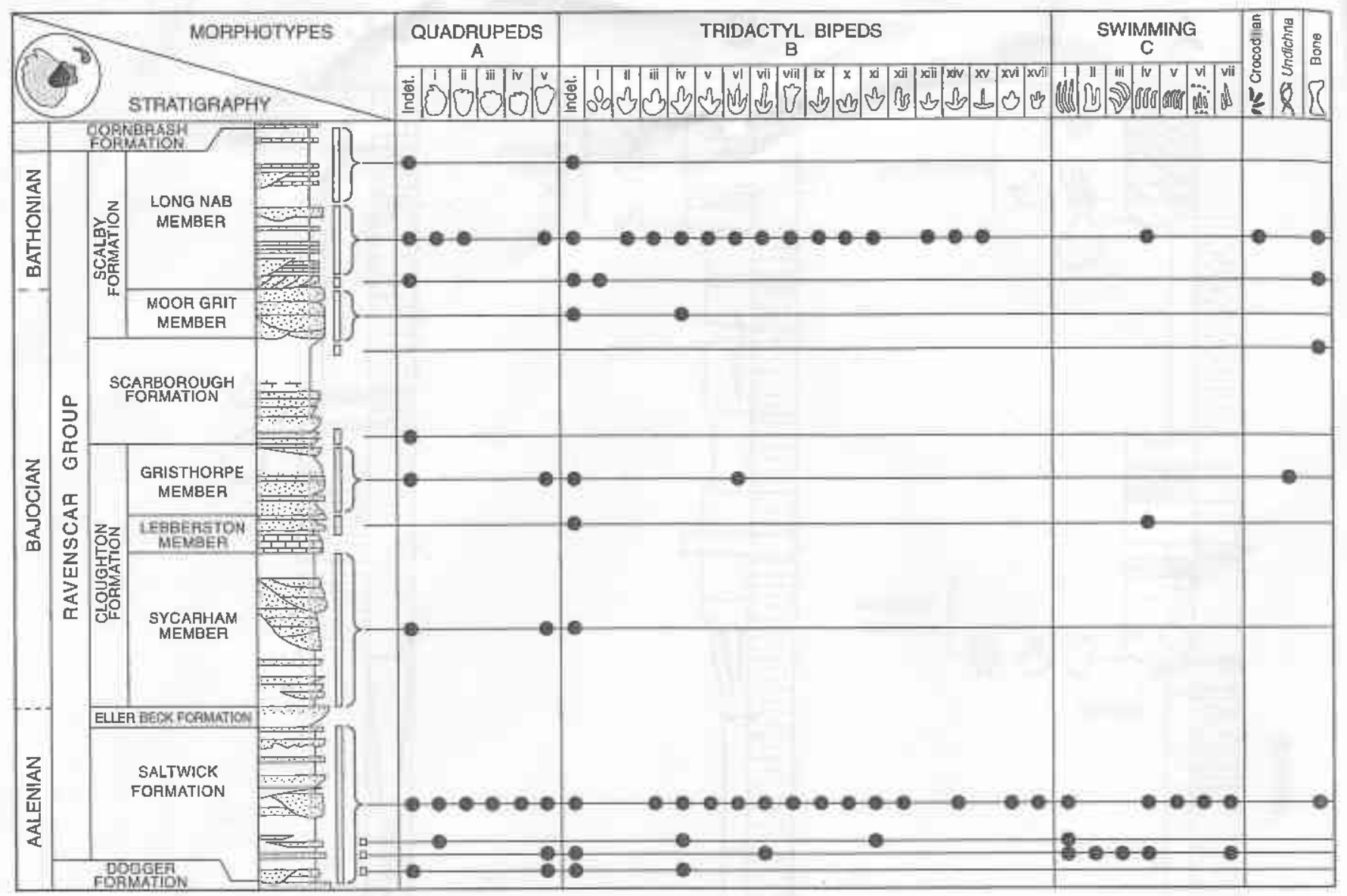

Fig. 24. Range chart showing the distribution of vertebrate tracks (Groups A, B and C) from the Middle Jurassic Ravenscar Group of the Cleveland Basin. Vertical bars to the right of the log indicate where the tracks have been found in situ or traced to their original stratigraphical level (short bars), or found loose and have not been accurately placed within the sequence (long bars). Also shown are occurrences of crocodilian walking tracks, swimming traces of fish (Undichna) and dinosaurian bone.

Leeder 1978) and the sequences on either side of the channelfill deposits are difficult to relate to each other. Both tridactyl and Group A morphotype prints (Fig. 20) have been located within the channel deposits and on their upper surfaces. At Cromer Point a within-channel trackway of Group A (sauropod) prints is aligned orthogonally to the channel axis. Elsewhere within this channel, dinosaurs have moved on sloping sediment surfaces and caused downward displacement of sand, and one of the post-channel fill units has been completely dinoturbated.

The upper parts of the current-bedded sandstones (Fig. 23, B) are in places disturbed and in Burniston Bay these can be seen to be due to large transmitted tridactyl prints (possibly related to morphotype $\mathbf{B i}$, Fig. 20). Large siderite nodules within these sandstones contain indeterminate tridactyl prints (also recorded by Ivens \& Watson 1994). Smaller tridactyl prints have been detected in cross-bedded units slightly farther north and in places prints show evidence of having been made on sloping surfaces with downward displacement of sediment. Farther to the south, between Burniston Bay and Scalby Ness, these units contain not only a range of tridactyl prints but also a number of prominent trackways. The wellknown $11 \mathrm{~m}$ long Scalby Bay or 'Jackson Bay' trackway (Fig. 25; morphotype Bi, Fig. 20) consists of 9 tracks (track number 4 is missing) of a northward moving bipedal dinosaur (Delair \& Sarjeant 1985, fig. 3; Ivens \& Watson 1994, p. 13; Rawson \& Wright 2000 , fig. 26). This trackmaker may have been an ornithopod (sensu Weishampel et al. 1990). We have recently discovered a $13 \mathrm{~m}$ trackway (Fig. 26), now rather degraded, occurring approximately $530 \mathrm{~m}$ SSE of the 'Jackson Bay' trackway. Although the tracks in this latter trackway are preserved as transmitted features, with indistinct margins, their large size (up to $1 \mathrm{~m}$ long) and generally rounded outline suggests they were made by a sauropod.

In contrast the uppermost parts of the Long Nab Member at Gristhorpe are largely mudrocks and siltstones but include a number of thin (1-2 m thick) sandstone beds, which have been so highly dinoturbated that primary sedimentary structures have been almost completely obliterated (Fig. 23, C). The bases of these beds have commonly been loaded into the underlying finer sediments. Recognizable prints in these beds are all Group A prints (Fig. 20) though it is possible that here, as elsewhere, large bipedal dinosaurs were also involved. The highest of these sandstones, a sand-dominated heterolithic unit, is less markedly dinoturbated and is the source of some impressive deep sauropod prints. Immediately above this, small indeterminate tridactyl prints are present in a thin, thinly bedded sandstone and are the highest stratigraphically welllocated prints in the coastal exposures of the Ravenscar Group (Fig. 23, C).

The above three case studies illustrate graphically the sort of information from which the distribution chart (Fig. 24) has been constructed. In this, the different sandstones at the base 


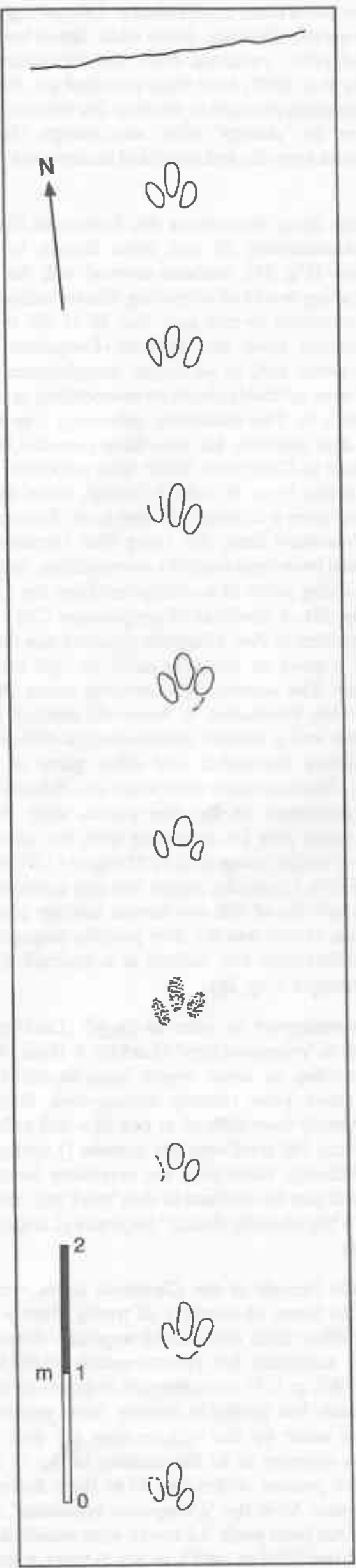

of the Saltwick Formation at Whitby (Fig. 23, A) have been plotted separately to reflect the type of data that may be derived from individual horizons. Elsewhere in the chart (Fig24), however, entries have been pooled to provide data for parts of the succession. The volume of data at different levels is uneven and the diverse ichnoassemblages in the Saltwick Formation and in the mid-Scalby Formation are a consequence of the greater areas of exposure of these units and perhaps also of our having given more time to their study. Despite this possible bias in the data, some interesting conclusions can be drawn about the distribution of the major morphotype groupings within the Ravenscar Group.

Though seldom well enough preserved and displayed to be assigned to one of the four relevant Group $\mathbf{A}$ morphotypes (Fig. 20, morphotypes Ai-Aiv), sauropod prints are widespread throughout the Ravenscar Group. As noted above they occur in several beds within the lower part of the Saltwick Formation and have also been recorded from beds, some of which are extensively dinoturbated, in the upper part of the Saltwick Formation at Hayburn Wyke. Within the Cloughton Formation they have been recorded by us from both the Sycarham and Gristhorpe members including, from the latter member, the very striking pes and manus prints in a highly carbonaceous mudrock or impure coal, which have been infilled by a white sandstone. Sauropod prints have also been recorded within the Helweth Beck Member of the 'marine' Scarborough Formation. However, they are perhaps most characteristic of, and abundant in, the Long Nab Member of the Scalby Formation (Figs 7, 16). They occur within and particularly on the upper surface of the 'Current Bedded Sandstones' and also within the 'Level Bedded Series'. In the latter they are present both within lenticular channel sandstones and also in sheet sandstones, which are commonly completely dinoturbated.

In contrast, the other quadrupedal track maker, which formed the prints assigned to Deltapodus brodricki (Whyte \& Romano 1993, 1994) and which was most probably a stegosaurian dinosaur (Whyte and Romano 2001), is most characteristic and widespread within the Saltwick Formation. However, the ichnogenus is not restricted to this formation (Fig. 24) and has been found in both of the non-marine members of the Cloughton Formation and in the Scalby Formation (Figs 6, 21, 22). Indeed the smallest Deltapodus print which has so far been documented, comes from the Long Nab Member of the Scalby Formation (section 5).

Tridactyl prints are widely dispersed throughout the sequence but, because of the problems of preservation, the full distribution of the various morphotypes is particularly difficult to establish. Records, such as those for the Saltwick Formation as a whole or for parts of the Scalby Formation (Fig. 24), show a wide range of morphotypes. Some common morphotypes (such as Bix; Figs 11,20) appear to have a long stratigraphical range and suggest that there has been broad constancy of

Fig. 25. Trackway made by a bipedal tridactyl dinasaur, exposed just below high water, near the middle of Sealby Bay [02989201] (Rawson \& Wright 2000, locality 48, fig, 26). The trackway is preserved on a sand bar within channel sandstones of the Long Nab Member (Sealby Formation). The trackway consists of eight preserved prints; the missing one has been reconstructed in the diagram (dotted omament). Direction of movement is towards the north. 


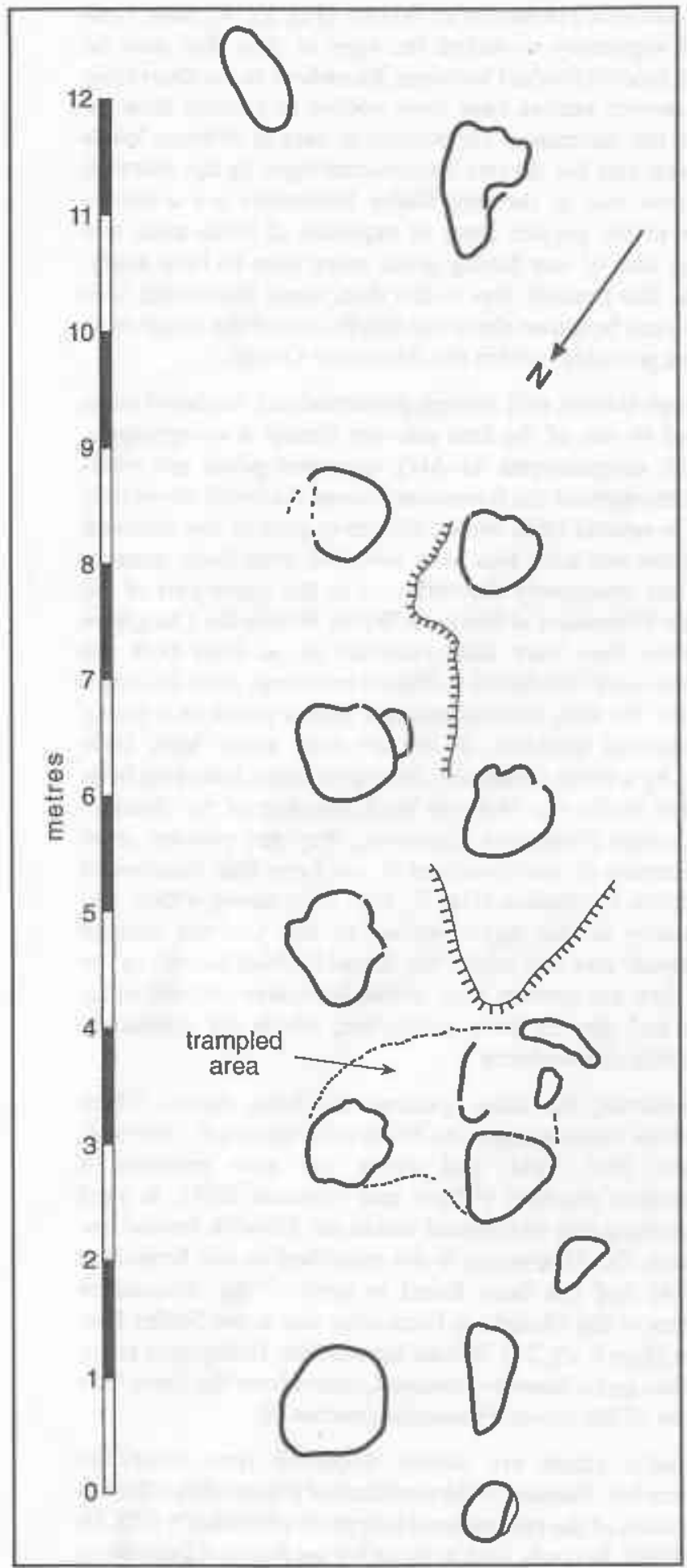

Fig. 26. Sauropod trackway exposed near high water mark, Scalby Bay [03169152], c. $530 \mathrm{~m}$ SSE of the trackway shown in Figure 25. The trackway is preserved on a sand bar within channel sandstones of the Long Nab Member (Scalby Formation), and consists of at least 12 aligned transmitted prints with the direction of movement towards the southeast. The distance apart of the prints denotes a 'wide-gauge' trackway (Farlow 1992).

bipedal dinosaur populations throughout the Ravenscar Group. However, though some large indeterminate tridactyl prints have been recorded from the Saltwick Formation, it is noticeable that the two largest tridactyl morphotypes have yet to be definitely recorded from this formation. Interestingly, no tridactyl prints from the Cleveland Basin which are as large as the megalosaurid prints recorded from the Bathonian of Oxfordshire (Day et al. 2002) have been recorded yet. Rarer, but distinctive, morphotypes such as the bird-like morphotype (Fig. 20, Bxv) or the 'chubby' print, morphotype (Bxvi), inevitably have more sporadic and restricted occurrences (Fig. 24).

Swimming prints occur throughout the Ravenscar Group but are most characteristic of and most diverse in the Saltwick Formation (Fig. 24). Surfaces covered with the distinctive parallel raking marks of swimming dinoturbation are also apparently restricted to this unit. Not all of the swimming traces recorded from the Saltwick Formation are necessarily dinosaurian and, in particular, morphotypes Civ to Cvii (Fig. 20) were probably made by crocodilians or chelonians (see section 5). The distinctive swimming type Civ, with its hooked digit imprints, has also been recorded from the Yons Nab Beds at Cloughton Wyke with associated tridactyl dinosaur prints (type $\mathbf{B}$ indet.), though these might have underprinted from a different surface level. Swimming traces, recently recorded from the Long Nab Member at Burniston, may also have been made by a crocodilian, and we have recorded walking prints of a crocodilian from the Long Nab Member (Fig. 24). A trackway of morphotype Cvii from the Saltwick Formation of Port Mulgrave provides one of the few instances of a body or tail drag-mark, though not of dinosaurian origin. The scarcity of swimming traces other than in the Saltwick Formation is, however, striking and suggests that there was a distinct environmental difference between the Saltwick Formation and other parts of the Ravenscar Group. Perhaps there were more water bodies in the Saltwick environment or flooding events were more persistent. This might also be consistent with the upward trend for increased aridity recognized by Morgans (1999) and Morgans et al. (1999). Curiously, traces that can confidently be linked to the activity of fish are almost entirely absent from the Ravenscar Group and the only possible example of the sinuous trace Undichna was noticed in a mudrock from the Gristhorpe Member (Fig. 24).

It has become customary to refer to 'large' (Lockley \& Gillette 1989, p. 5) or 'megatracksites' (Lockley \& Hunt 1995, p. xiv) when referring to areas where large numbers of tracks/trackways have been reliably documented. Such a tracksite has arbitrarily been defined as one in which at least 1000 tracks or about 100 trackways are present (Lockley \& Gillette 1989). Although these sites are invariably laterally extensive, the prints may be confined to thin 'track rich zones' or occur through a "significantly thicker' sequence (Lockley \& Hunt 1995, p. 297).

Does the Middle Jurassic of the Cleveland Basin qualify for such a title? In terms of numbers of tracks there is no doubt that the $c .200 \mathrm{~m}$ thick non-marine sequence (Rawson \&. Wright 2000), extending for approximately $10,000 \mathrm{~km}^{2}$ (Bradshaw et al. 1992, p. 117), contains well in excess of 1000 tracks. This number has probably already been exceeded from observations made by the authors over the past ten years. As a crude estimate as to the number of tracks and trackways that are present within the $57 \mathrm{~m}$ thick Saltwick Formation, print data from the 'Deltapodus sandstone' discussed previously has been used. All tracks were recorded on fallen blocks. The bed ( $0.85 \mathrm{~m}$ thick), in which these ichnites 
are preserved, extends for $100 \mathrm{~m}$ along the cliff. Assuming that the 27 recorded tracks of $D$. brodricki were recovered from a $2 \mathrm{~m}$ wide band that had fallen from the cliff and that the unit has a lateral extension of approximately $10,000 \mathrm{~m}^{2}$ $(100 \times 100 \mathrm{~m})$, then approximately 1350 tracks of $D$. brodricki occur in $1.5 \%$ of the Saltwick Formation. If these figures have any meaning, then clearly the Middle Jurassic of the Cleveland Basin would qualify for such a title as a "megatracksite'. If other beds had been chosen, such as the 'swimming bed' (Whyte \& Romano 2002), where up to 20 tracks per $\mathrm{m}^{2}$ are not uncommon (and commonly a far greater density), then estimates would have been orders greater. Lockley \& Hunt (1995, p. 154-5) argued that megatracksites tend to be associated with the boundaries between formations and in particular with 'some type of unconformity or hiatus'. The authors have noticed no such association in the Middle Jurassic sequence of Yorkshire.

Whether the Middle Jurassic of the Cleveland Basin qualifies as a 'megatracksite' with respect to numbers of trackways is less certain. Undoubtedly extensive trackways are present in the Yorkshire Middle Jurassic sequence but the style and extent of exposures makes it very unlikely that examples of herding (Lockley \& Hunt 1995, fig. 5.20), stampedes (Thulborn \& Wade 1979) or even very long single trackways (Santos et al. 1994) will ever be recorded from the rocks of the Cleveland Basin. The frequency of track layers in a sequence may also be used to gauge the numbers of tracks present. Lockley (1991b, figs 8.3, 8.5), Lockley \& Hunt (1995, figs 5.18, 5.47) and Lockley \& Meyer (2000, fig. 7.13) indicated frequency of print layers at various sites throughout the world, using logs on a variety of scales, and Ensom (1982, p. 141; 1995, p. 80) recognized from ten print layers in $25 \mathrm{~m}$, to four (?five) print layers in $0.332 \mathrm{~m}$ in the Purbeck Limestone Group of southern England. The frequency of track layers in the non-marine units of the Ravenscar Group is at times directly comparable to that recorded by Ensom, and in the Long Nab Member at the northern end of Burniston Bay, at least nine print horizons have been recorded in a heterolithic sequence just over one metre thick. Prints tend to be much more abundant in heterolithic facies and along junctions between contrasting lithotypes (Fig. 23, A-C), although their apparent absence or rarity in homolithic facies may simply reflect the reduction in preservational potential.

We conclude from the above discussion, that the assignation of the title 'megatracksite' to the Yorkshire sequence is justified and that the area qualifies as a site of global importance.

During the course of these studies the authors have discovered a few pieces of bone (Fig. 24) that range from small fragments to a nearly complete sauropod vertebra. The authors, with Dr Phil Manning, are presently describing this material. In view of the abundance and diversity of dinosaur prints, it is perhaps surprising that dinosaur skeletal elements are so rare in the Ravenscar Group. An important factor in the non-preservation of bone may have been the acidity of the soils and groundwaters. Interestingly, the global record of Middle Jurassic dinosaur bone is also extremely sparse (Romer 1966; Weishampel et al. 1990; Benton 1993) and this underlines the international importance of the Yorkshire prints in helping to determine the nature of contemporary dinosaur communities.

\section{DINOSAUR DIVERSITY AS DEDUCED FROM THE TRACKS}

The diversity of the dinosaur populations that were present in the Yorkshire area during the Middle Jurassic, and which gave rise to the range of track morphotypes found in the rocks of the Cleveland Basin, remains to be addressed. Although it is not intended here to discuss the likely maker of each morphotype, some general comments are required to indicate the possible range of dinosaur types and communities that inhabited this Middle Jurassic coastal plain and fluvial complex. Despite the obvious attractions and desirability of assigning a maker to each type of track, the authors concur with others (Farlow \& Chapman 1997, p. 538) that only rarely will this prove possible. Indeed Allen (1997, p. 514) concluded that only a very small percentage of prints yield "unchallengeable taxonomic information' about their makers. However, even though the assignation of track morphotypes to makers at specific or generic level will generally remain an unobtainable goal, the authors believe that recognition of the maker occasionally may be achieved at least to family level.

Three major groups of prints have been recognized (Fig. 20 ), based on a combination of morphological features of the prints and inferred behaviour of the maker (section 5). Implicit in this classification is the acceptance that morphotypes from two different groups (Group $\mathbf{C}$ and $\mathbf{A}$ or $\mathbf{B}$ ) may well have been made by the same (or same type of) animal.

The morphotypes within Group A (Fig. 20, Ai-iv) are those made by habitual quadrupeds. They indicate that at least two different types of sauropod were probably present at this time (Romano et al. 1999). The Brontopodus-type (Fig. 20, Ai) wide-gauge trackways have been regarded by Farlow et al. (1989), Farlow (1992) and Moratalia et al (1994) as having been made by brachiosaurs (a camarasaur). While the narrowgauge trackways of Breviparopus-type (Fig. 20, Aii, Aiii) indicate a different sauropod group with limbs that were angled inwards (Farlow 1992). There is even the slight possibility that a third sauropod type may have been present and that it is represented by the morphotype shown here as Type Aiv (Fig. 20, and fig. 3D in Romano et al. 1999). The localized abundances of sauropod prints may indicate gregarious behaviour. The smallest sauropod footprints recorded are about $0.5 \mathrm{~m}$ in width, i.e. approximately half the size of the largest sauropod prints and the lack of smaller prints is puzzling especially as prints of other smaller bipedal dinosaurs are abundant. This may indicate that juvenile sauropods lived apart from the adults and outside the depositional basin (section 5). The final print type of this group (Fig. 20, Av), assigned to the ichnotaxon Deltapodus brodricki (Whyte \& Romano 1995), appears at present to be endemic to the Cleveland Basin and is suggested to be a record of a Jurassic stegosaurian dinosaur (Whyte \& Romano 2001). The panorama (Fig. 27), therefore, includes two sauropod species and a stegosaurian.

The range of possible makers for the prints in Group B (Fig. 20 ) is more difficult to predict, since our detailed studies of the tridactyl prints is at a relatively early stage. Features such as claw imprints shape and angle of divarification of digit imprints and presence of phalangeal pads serve to provide the basis for subdivision into a number of subgroups. For example, morphotypes Biii, Bvi, Bix, Bxii, Bxiv and possibly Bxv (Fig. 20) all 
imprints and so may be distinguished (on a morphological/ taxonomic basis) from those prints with rounded digit ends. The former are considered to have been made by theropod dinosaurs, whereas the latter are provisionally attributed to ornithopods. Within the 'theropod morphotypes', it is possible to further distinguish more slimly built "gracile" forms (such as Bvi, Bix, Bxiv, Bxv) from more 'robust' forms (Biii). 'Ornithopod morphotypes' have been recognized on the basis of broad digit imprints, and the absence of claw marks; morphotypes Bi and Biv illustrate this type. Another feature that may be used to separate subgroups within Group $\mathbf{B}$ is the presence of forwardly and evenly tapering digit imprints. In particular, morphotypes Bii, Biii, Bv and Bxvi show this particularly well. The divarification of the digit imprints is another possibly useful characteristic that may ultimately prove useful to diagnose morphotypes. The extremes of total divergence of the outer digits are represented by morphotypes Bxii (subparallel) and Bxv (broadly splayed). The latter are among the most distinctive tridactyl prints from the Cleveland Basin and compare with the bird-like track of Lockley \& Hunt (1995, fig. 4.33B). Rare specimens exhibiting well-marked metatarsal imprints are represented by morphotype Bviii. Although distinctive, this morphotype may be either a plantigrade behavioural variant or, more likely, the result of deep penetration in the sediment and a shallow-level print preservation (see section 4). Thus, in this panorama (Fig. 27), a minimum of four bipedal dinosaurs have been provisionally recognized as inhabitants of the Cleveland Basin; two theropods and two ornithopods, each type being represented by large and small forms.

The morphotypes included within Group C (Fig. 20) are tracks resulting essentially from a swimming behavioural pattern. As swch they are all characterized by possessing parallel digit scratch marks that do not yield much useful taxonomic information. Some were probably made by animals already recognized in groups $\mathbf{A}$ or $\mathbf{B}$. For example, morphotype $\mathbf{C i}$ has been interpreted as having been made by a dinosaur whose more normal walking tridactyl track has already been described (Whyte \& Romano 2002) and may be assigned to $\mathbf{B x}$. The large, straight to curved digit traces of $\mathbf{C i}$ and $\mathbf{C i i i}$ compare in size with those of $\mathbf{A v}$ and could possibly represent the swimming traces of a Jurassic stegosaurian dinosaur. The four other morphotypes in this group (Fig. 20, Civ-Cvii) are characterized by having curved digit imprint terminations and/or imprints of two or four digits. These are considered to be examples of non-dinosaurian prints and could represent both crocodilian (Civ-Cvi) and chelonian (Cvii)

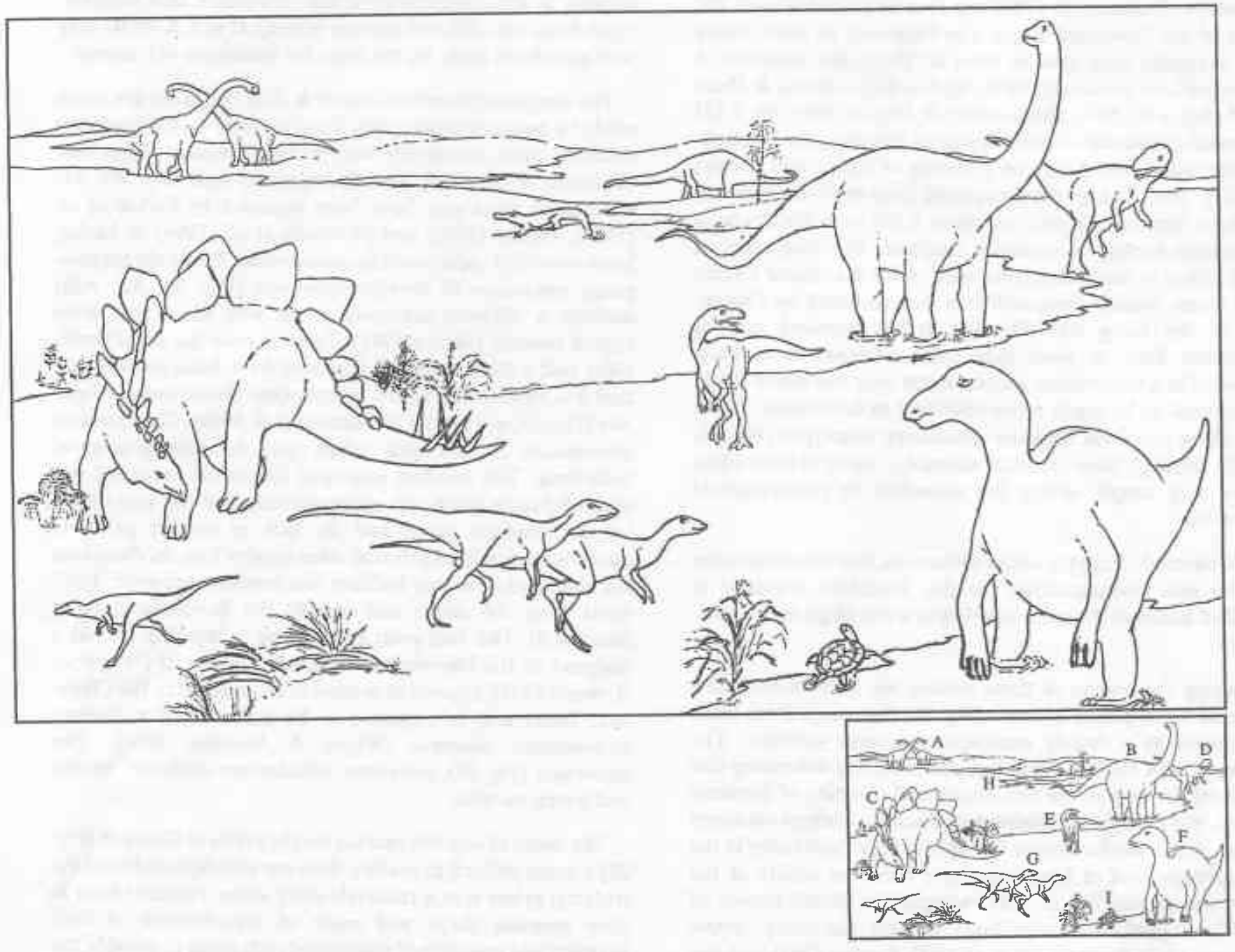

Fig. 27. Panorama showing possible dinosaur community that inhabited the Cleveland Basin during the Middle Jurassic. Representatives of the following groups of dinosaurs are included: sauropods (two types; A, B), stegosaunid (C), theropods (two types; D, E), onithopods (two types; $F, G)$. Also included are examples of a crocodilian $(\mathrm{H})$ and a chelonian $(\mathrm{I})$. 
tracks (Fig. 27). The authors have specimens of undoubted crocodilian walking tracks and these, together with the examples in Group $\mathbf{C}$, will be described at a later date.

We are not at present in a position to discuss Yorkshire Middle Jurassic dinosaur communities in a meaningful way. To recognize a community, it would need to be a certainty that particular ichnoassemblages were all more or less contemporaneous, and to complete the picture, it would be desirable to be able to reconstruct the associated palaeoenvironments. Until such ichnofacies can be recognized and defined, it is preferential to present a combined picture that illustrates a provisional range of dinosaur types in a generalized habitat. Figure 27 presents the authors' latest, albeit rather conservative impression of the likely dinosaur types that at one time inhabited the coastal plain and fluvial complex of the Cleveland Basin. This work has gone a long way towards improving the knowledge of a hitherto poorly known global record of Middle Jurassic dinosaurs and work in progress will undoubtedly refine this picture; a picture that has emerged solely from studies of dinosaur tracks and trackways.

Acknowledgements. During our work on the Yorkshire coast over the past 15 years, numerous people, too many to mention by name, have contributed to extending our database by recording and reporting specimens they have observed in the field or collected. To these we would like to express our thanks for their willingness to help and share their finds. However, we wish to acknowledge in particular the more regular help from Richard Myerscough, Mr Paul Ensom, our past and present research students (Dr Phil Manning, Danny Elvidge, Simon Jackson, Steve Holroyd, Dr Mike Snook, Dr Matthew Porter), Byron Blessed, Mr Peter Robinson, Mr Nigel Whittington, Dr Robin Scott, Stewart Marsden, volunteers of Earthwatch International and those keen and dedicated people who, on numerous geological field parties (Yorkshire Geological Society, British Association for the Advancement of Science, Geologists' Association, Leeds Geological Association, Leicester Geological Society, Dinosaur Society, Sheffield University Geological Society), have left no stone unturned in an attempt to uncover just one more specimen. Thanks are also extended to Ms Ruth Hughes for conducting our first laboratory experiments and for showing us their potential. Technical help received from Paul Coles, Mike Cooper, Rob Ashurst and Barry Pigott is gratefully acknowledged. Finally, we wish to acknowledge the generous support from the Nuffield Foundation and Earthwatch Intemational.

\section{APPENDLX}

Given below are brief descriptions of 29 morphotypes of dinosaur and other vertebrate tracks currently recognized by the authors from the Middle Jurassic of the Cleveland Basin (Fig. 20). Unless otherwise stated, all the types represent pes tracks.

We have resisted referring to these descriptions as diagnoses since, for the tridactyl tracks in particular, these studies have not yet clearly distinguished in all cases between true morphotypes that merit ichnospecific status ('track-specific' and behavioural types) and preservational variants. Hence the descriptions incorporate size terms that ultimately may not prove to be important taxonomic criteria.
Where morphotypes are sufficiently well-known and with adequate material, they are assigned to a named ichnotaxon; uncertainty is jindicated by inverted commas. The morphotypes have been provisionally divided into three main groups (A, B, C) for descriptive purposes only and are not intended to be indicative of an ichnological classification. We fully appreciate that morphotypes from two different groups may well have been made by the same animal. All outlines (Fig. 20) are taken from actual prints recorded in the field by the authors. Morphological variation (such as divergence of digit imprints, size of print), geographical location, stratigraphical level and specimen number are given for each print when known. Note that the scale on Figure 20 is different for Group A prints than those for Groups B and C.

\section{Group A}

Prints included in this group were all made by habitual quadrupeds. In a number of cases (Aiii, Av) prints of both pes and manus are known.

Ai Very large (up to $1 \mathrm{~m}$ ) sub-oval print with up to five digit imprints, commonly backwardly curved and reducing in size from front to back. ('Brontopodus', Romano et al. 1999, fig. 3A). Jump Down Bight, Whitby; Saltwick Formation.

Aii Very large (up to $0.8 \mathrm{~m}$ ) bell-shaped pes print with up to five digit imprints, commonly curved, along the straight anterior margin. ('Breviparopus', Romano et al. 1999, fig. 3B). Jump Down Bight, Whitby; Saltwick Formation.

Aiii Very large (up to $0.6 \mathrm{~m}$ ) bell-shaped pes print with up to five curved digit impressions along the front margin and down the outer lateral margin. Manus print broadly semi-circular in outline, with one or two indentations on anterior margin and up to two on posterior margin. Manus placed in 'approximate' position; actual relationship not known. (Possible preservational variant of Aii. Romano et al. 1999, fig. 3Ci, iv). NW of Maw Wyke, Hawsker Bottoms; Saltwick Formation.

Aiv Large (up to $0.5 \mathrm{~m}$ ) 'U-shaped' print, with up to five curved digit impressions along the front margin and down the outer lateral margin. (Possible preservational variant of Aii, Romano et al. 1999, fig. 3D). Rail Hole Bight, Whitby; Saltwick Formation.

Av Large (up to $0.5 \mathrm{~m}$ ) pes print, generally triangular in outline; mesaxonic with three short digit imprints. Some have concave inner margin to print and small digit impression on outer lateral margin. Manus print entaxonic, irregular but broadly crescentic in outline, occasional inwardly directed ?pollex impression. (Deltapodus brodricki Whyte \& Romano, 1995). Holotype figured F00768; see Whyte \& Romano (1995, figs 5, 8A). Rail Hole Bight, Whitby; Saltwick Formation.

\section{Group B}

All prints included here are markedly tridactyl and were made by habitual bipeds. It is assumed provisionally that all of the prints are those made by the pes. However, it is possible that some (such as Bxvii) may turn out to be that of a manus.

Bi Large (up to $45 \mathrm{~cm}$ ) mesaxonic print, consisting of separate and radiating oval digit impressions. No indication of a heel mark. Middle of Scalby Bay; Long Nab Member, Scalby Formation. 
Bii Large (up to $35 \mathrm{~cm}$ ) mesaxonic print, with tapering digit imprints and claw-like terminations. Lateral digits of more or less equal divergence $\left(40^{\circ}\right)$. North end of Scalby Bay; Long Nab Member, Scalby Formation. (Specimen F00793, University of Sheffield).

Biii Medium (up to $25 \mathrm{~cm}$ ) mesaxunic print, with broad digit imprints, terminating in claws. Straight outer margin of digit IV(?). Heel mark well-defined. (Satapliasaums dsocenidtei Gabouniya, 1951; but see comments by Lockley \& Meyer 2000, p. 134). Specimen figured in Romano \& Whyte (1996, fig.2f). Rail Hole Bight, Whitby; Saltwick Formation.

Biv Medium (up to $25 \mathrm{~cm}$ ) mesaxonic print, with sub-parallel to slightly tapering broad digit imprints and rounded terminations. Lateral digit (?II) directed more outwards. (Print A, Whyte \& Romano 2002). Specimen figured in Romano \& Whyte (1996, fig. 2g). Rail Hole Bight, Whitby; Saltwick Formation.

Bv Medium (up to $30 \mathrm{~cm}$ ) mesaxonic print, with narrowing middle digit impression showing constrictions (pads). Lateral digits divergent and apparently with rounded terminations (cf. 'Eubrontes'). Port Mulgrave; Saltwick Formation.

Bvi Medium (up to $20 \mathrm{~cm}$ ) mesaxonic print, with relatively slender digit imprints. Outer digits slightly divergent, with phalangeal pads and terminal claws. Some tracks with rounded pad-like heel print. Yons Nab; Gristhorpe Member, Cloughton Formation (Fig. 12).

Bvii Medium (up to $20 \mathrm{~cm}$ ) mesaxonic print, with relatively long central digit imprint $c .75 \%$ of total print length. Digit terminations evenly rounded. Posterior margin evenly rounded. Whitby; Saltwick Formation.

Bviii Medium (less than $20 \mathrm{~cm}$ ) mesaxonic print with short digit imprints and long metatarsal imprint. Port Mulgrave; Saltwick Formation.

Bix Medium (up to $15 \mathrm{~cm}$ )) tridactyl, mesaxonic print, with slim (gracile) and distally pointed digit imprints indicating terminal claw. Distal part of digit II imprint outwardly curved, digit IV imprint gently curved; indications of phalangeal pads: Angle between digit imprints II and IV c $80^{\circ}$. Indistinct heel mark. (Whyte \& Romano 1981, figs 3, 4; F00766). Black Rocks, S. of Scarborough; Long Nab Member, Scalby Formation (Fig. 11).

Bx Medium (up to $15 \mathrm{~cm}$ ) mesaxonic print, with fairly short and broad digit impressions. Distal part of digit II imprint outwardly curved. Port Mulgrave; Saltwick Formation.

Bxi Small (c. $10 \mathrm{~cm}$ ) mesaxonic print, with tapering digit imprints, divergent outer digits $\left(85-100^{\circ}\right)$ and pronounced triangular-shaped heel print. Middle digit imprint between $50-60 \%$ of total print length. Port Mulgrave; Saltwick Formation.

Bxii Small (c. $10 \mathrm{~cm}$ ) mesaxonic print, with subparallel digit imprints. Well-marked phalangeal pads (cf. 'Grallator'). Port Mulgrave; Saltwick Formation.

Bxiii Small (less than $10 \mathrm{~cm}$ ) anchor-like mesaxonic print, with tapering digit imprints and widely divergent (c. $85^{\circ}$ ) outer digit imprints. Rounded heel mark. Scalby Bay; Long Nab Member, Scalby Formation.

Bxiv Small (less than $10 \mathrm{~cm}$ ) mesaxonic print, with slim and widely divergent $\left(105^{\circ}\right)$ outer digit imprints. Middle digit strongly tapered (?clawed). Distal part of outer digit with lateral curvature. No clear heel imprint. Port Mulgrave; Saltwick Formation.

Bxv Small (less than $10 \mathrm{~cm}$ ) mesaxonic 'bird-like' print, with strongly divergent (c. $145^{\circ}$ ) outer digit imprints. Digit imprints generally slender and with phalangeal pads. No clear heel imprint. Scalby Bay; Long Nab Member, Scalby Formation.

Bxyi Small (less than $10 \mathrm{~cm}$ ) mesaxonic print, with broad and rapidly narrowing digit imprints. Rounded heel imprint. Hawsker; Saltwick Formation.

Bxvii Small (less than $10 \mathrm{~cm}$ ) barely mesaxonic print, with slim digit imprints only a little divergent. Possible rounded heel imprint. Port Mulgrave; Saltwick Formation.

\section{Group C}

All prints included here show between 2 and 4 pes digit imprints that are essentially parallel. They are interpreted as resulting from a swimming behaviour.

Ci Medium (up to $25 \mathrm{~cm}$ ) print, consisting of three elongate (hypichnial) ridges which may be straight, gently curved or sinuous. The termination of the ridges may be sharp or sharply reflexed. (Characichnos tridactylus Whyte \& Romano, 2002). Part of holotype trackway; see also associated specimen in same trackway in Romano \& Whyte (1996, fig. 2c). Rail Hole Bight, Whitby; Saltwick Formation.

Cii Medium to large (up to $35 \mathrm{~cm}$ long) print, consisting of two (or more) straight, sub-parallel, parallel-sided digit imprints which are joined transversely at one end. Long Bight, Whitby; Saltwick Formation.

Ciii Medium (up to $30 \mathrm{~cm}$ long) print, consisting of three curved, sub-parallel, generally parallel-sided digit imprints which are joined transversely at one end. Long Bight, Whitby; Saltwick Formation.

Civ Small to medium $(10-20 \mathrm{~cm})$ print consisting of three short, broad and tapering, parallel digit imprints with hooked ends; more or less straight posterior margin. Cloughton Wyke; Cloughton Formation. Crocodilian print.

Cv Small (less than $10 \mathrm{~cm}$ ) print, consisting of up to four, closely spaced (hypichnial) ridges, narrowing laterally and distally curved. Port Mulgrave; Saltwick Formation. Crocodilian print.

Cvi Small (less than $10 \mathrm{~cm}$ ) pes print, consisting of up to three sub-parallel digit imprints ending posteriorly with subcircular (hypichnial) mounds. Manus print (less than $10 \mathrm{~cm}$ ) consisting of up to four discrete mounds arranged in a forwardly directed curve. Port Mulgrave; Saltwick Formation. Possible crocodilian print.

Cvii Small (less than $10 \mathrm{~cm}$ ) prints, consisting of two short, tapering digit imprints. Other end swollen and may be joined to adjacent ridge. Long Bight, Whitby; Saltwick Formation. Chelonian print.

\section{REFERENCES}

ALEXANDER, J. 1986. Idealised flow models to predict alluvial sandstone body distribution in the Middle Jurassic Yorkshire Basin. Marine and Petroleum Geology, 3, 298-305.

ALEXANDER, J. 1987. Syn-sedimentary and burial related deformation 
in the Middle Jurassic non-marine formations of the Yorkshire Basin. In. Jones, M. E. \& Preston, R. M. F. (eds) Deformation of Sediments and Sedimentary Rocks. Geological Society, London, Special Publications, 29, 315-324.

ALEXANDER, J. 1989. Delta or coastal plain? With an example of the controversy from the Middle Jurassic of Yorkshire. In: Whateley, M. K. G. \& PICKERING, K. T. (eds) Deltas: Sites and Traps for Fossil Fuels. Geological Society, London, Special Publications, 41, 11-19.

ALEXANDER, J. 1992. A discussion of alluvial sandstone body characteristics related to variations in marine influence, Middle Jurassic of the Cleveland Basin, UK, and the implications for analogous Brent Group strata in the North Sea Basin. In: Morton, A. C., Hazeldine, R. S., Giles, M. R. \& Brown, S. (eds) Geology of the Brent Group. Geological Society, London, Special Publications, 61, 149-167.

ALEXANDER, J. \& GAWTHORPE, R. L. 1993. The complex nature of a Jurassic multistorey, alluvial sandstone body, Whitby, North Yorkshire. In: NorTH, C. P. \& Prosser, D. J. (eds) Characterization of Fluvial and Aeolian Reservoirs. Geological Society, London, Special Publications, 73, 123-142.

AleXANDER, R. MCN. 1976. Estimates of speeds of dinosaurs. Nature, 261, 129-130.

AleXANDER, R. MCN. 1985. Mechanies of posture and gait of some large dinosaurs. Zoological Joumal of the Linnean Society, 83, $1-25$.

ALLEN, J. R. L. 1997. Subfossil mammalian tracks (Flandrian) in the Severn Estuary, S.W. Britain: mechanics of formation, preservation and distribution. Philosophical Transactions of the Royal Society of London, B352, 481-518.

AVANZINI, M. 1998. Anatomy of a Footprint: Bioturbation as a Key to Understanding Dinosaur Walk Dynamies. Ichnos, 6, 129-139.

BATE, R. H. 1978. The Jurassic Part II - Aalenian to Bathonian. In: BATE, R. H. \& RoBinson, E. (eds) A stratigraphical index of British Ostracoda. Geological Joumal, Special Issue, 8, 213-258.

Benton, M. J. 1993. Reptilia. In: Benton, M. J. (ed.) The Fossil Record 2. Chapman \& Hall, London, 681-715.

Benton, M. J. 1996. The Penguin Historical Atlas of the Dinosaurs. Penguin Group, London.

BLACK, M. 1929. Drifted plant-beds of the Upper Estuarine Series of Yorkshire. Quarterly Joumal of the Geological Society, London, 85, 389-437.

Black, M., Hemingway, J. E. \& WiLson, V. 1934. Summer field meeting to North East Yorkshire, August $9^{\text {th }}$ to $20^{\text {th }}$. Proceedings of the Geologists' Association, 45, 298-299.

Bradshaw, M. J., Cope, J. C. W., Cripps, D. W., Donovan, D. T., HOWARTH, M. K., RAWSON, P. F., WEST, I. M. \& WIMBLEDON, W. A. 1992. Jurassic. In: COPE, J. C. W., INGHAM, J. K. \& RAwsON, P. F. (eds) Atlas of Palaeogeography and Lithofacies. Geological Society, London, 107-129.

Brodrick, H. 1907. A find!!! Report of the Whitby Philosophical Society, $85,8-9$.

Brodrick, H. 1908. Note on further footprint casts found in the Inferior Oolite at Saltwick. Report of the Whitby Philosophical Society, 86, 6-7.

Brodrick, H. $1909 a$. Note on Casts of Dinosaurian Footprints in the Lower Oolite at Whitby. Report of the British Association for the Advancement of Science (Dublin 1908), 707-708.

BRoDRICx, H. 1909b. Note on Footprint casts from the Inferior Oolite near Whitby, Yorkshire. Proceedings of the Liverpool Geological Society, 10, 327-335.

CARPENTER, K. 1999. Eggs, nests and baby dinosaurs: a look at dinosaur reproduction. Indiana University Press, Bloomington and Indianopolis.

Casamiquela, R. M., Demathieu, G. R., Haubold, H., Leonardi, G. \& SARJEANT, W. A. S. 1987. In: G. LeONARDI (ed.) Glossary and Monual of Tetrapod Footprint Palaeoichnology. Departamento Nacional da Produçăo Mineral, Brasilia [in English, with glossary in eight languages].

Chure, D., Turner, C. \& Peterson, F. 1994. An embryo of Camp- tosaurus from the Morrison Formation (Jurassic, Middle Tithonian) in Dinosaur National Monument, Utah. In: CARPENTER, K., Hirsch, K. F. \& Horner, J. R. (eds) Dinosaur Eggs and Babies. Cambridge University Press, Cambridge, 298-311.

COPE, J. C. W., GetTy, T. A., Howarth, M. K., Morton, N. \& Torrens, H. S. 1980a. A correlation of Jurassic rocks in the British Isles Part One: Introduction and Lower Jurassic. Geological Society, London, Special Report, 14.

Cope, J. C. W., DufF, K. L., Parsons, C. F., Torrens, H. S., WLmbledon, W.A.\& WRIGHT, J. K. $1980 b$. A correlation of Jurassic rocks in the British Isles Part Two: Middle and Upper Jurassic. Geological Society, London, Special Report, 15.

DAY, J. J., Norman, D. B., UPChURCH, P. \& POWELL, H. P. 2002. Dinosaur locomotion from a new trackway. Nature, 415, 494-495.

DELAIR, J. B. \& SARJEANT, W. A. S. 1985. History and bibliography of the study of fossil vertebrate foorprints in the British Isles: Supplement 1973-1983. Palaeogeography, Palaeoclimatology, Palaeoecology, 49, 123-160.

DiNGLE, R. V. 1971. A marine geological survey off the north-east coast of England (western North Sea). Joumal of the Geological Society, London, 127, 112-170.

Dodson, P. 1996. The homed dinosaurs: a natural history. Princeton University Press, New Jersey.

DODSON, P., BEHRENSMEYER, A. K., BAKKeR, R. T. \& MCINTOSH, J. S. 1980. Taphonomy and paleoecology of the dinosaur beds of the Jurassic Morrison Formation. Paleobiology, 6, 208-232.

Ensom, P. C. 1982. Dinosaut Footprints at 19 Townsend Road, Swanage, in 'Dorset Geology in 1981'. Proceedings of the Dorset Natural History and Archaeological Society, 103, p. 141.

ENsom, P. C. 1983. Ichnites spp. from the Chief Beef Beds and Broken Shell Limestone, Durlston Beds, Purbeck Limestone Formation, Duriston Bay, Swanage, in 'Dorset Geology in 1982'. Proceedings of the Dorset Natural History and Archaeological Society, 104, p. 201.

ENsom, P. C. 1995. Dinosaur Footprints in the Purbeck Limestone Group (?Upper Jurassic - Lower Cretaceous) of Southern England. Proceedings of the Dorset Natural History and Archaeological Society, 116, 77-104.

Eschard, R., RavenNe, C, Houel, P., \& KNox, R. 1991. Threedimensional reservoir architecture of a valley-fill sequence and a deltaic aggradational sequence: influences of minor relative sea-level changes. In: MIAIL, A. D. \& TYLER, N. (eds) The three-dimensional facies architecture of terrigenous clastic sediments and its implications for hydrocarbons discovery and recovery. SEPM, Concepts in Sedimentology, 3, 133-147.

FARLOW, J. O. 1992. Sauropod tracks and trackmakers: integrating the ichnological and skeletal records. Zubia, 10, 89-138.

FARLOW, J. O. \& CHAPMAN, R. E. 1997. The scientific study of dinosaur footprints. In: FARLOW, J. O.\& BRETT-SURMAN, M. K. (eds) The complete dinosaur. Indiana University Press, Bloomington \& Indianapolis, 519-553.

FARLOW, J. O. \& LockLEY, M. 1989. Roland T. Bird, Dinosaut Tracker: An Appreciation. In: GilletTE, D. D. \& LOCKLEY, M. G. (eds) Dinosaur Tracks and Traces. Cambridge University Press, Cambridge, 33-36.

FARLOW, J. O., PTTTMAN, J. G. \& HAWTHORNE, J. M. 1989. Brontopodus birdi, Lower Cretaceous footprints from the U.S. Gulf Coastal Plain. In: GILLETTE, D. D. \& LockLey, M. G. (eds) Dinosaur Tracks and Traces. Cambridge University Press, Cambridge, 371-394.

Fox-STRANGWAYs, C. 1880. The geology of the Oolitic and Cretaceous rocks south of Scarborough. Memoir of the Geological Survey, England and Wales, Sheets 54, 55.

Fox-STRANGWAYs, C. 1892. The Jurassic rocks of Britain. Memoir of the Geological Survey, England and Wales.

Fox-Strangways, C. 1904. The geology of the Oolitic and Cretaceous rocks south of Scarborough (2nd edition). Memoir of the Geological Survey, England and Wales, Sheets 54, 55. 
Fox-Strangways, C. \& BarRow, G. 1915. The geology of the country between Whitby and Scarborough (2nd edition). Memoir of the Geological Survey, England and Wales, Sheets 35, 44.

GAtesy, S. M., Middleton, K. M., Jenkins, F. A. \& ShubIN, N. H. 1999. Three-dimensional preservation of foot movements in Triassic theropod dinosaurs. Noture, 399, 141-144.

Goldring, R \& Pollard, J. E. 1995. A re-evaluation of Ophiomorpha burrows in the Wealden (Lower Cretaceous) of southern England, Cretaceous Research, 16, 665-680.

HanCoCK, N. J. \& Fisher, M. J. 1981. Middle Jurassic North Sea deltas with particular reference to Yorkshire. In: ILLING, L. V. \& Hobson, G. D. (eds) Petroleum Geology of the Continental Shelf of North-West Europe. Institute of Petroleum, London, 186-195.

HÃrzzchel, W. 1975. Trace fossils and Problematica. In: Teichert, $C$, (ed.) Treatise on invertebrate paleontology, Part W, Miscellanea, Supplement 1. Geological Society of America, Boulder, \& University of Kansas Press, Lawrence.

Hargreaves, J. A. 1913. Fossil footprints near Scarborough. The Naturalist, 673, 92-95.

Hargreaves, J. A. 1914. Fossil footprints near Scarborough. The Naturalist, 688, 154-156.

HemingwaY, J. E. 1949. A revised terminology and subdivision of the Middle Jurassic rocks of Yorkshire. Geological Magazine, 86, 67-71.

Hemingway, J. E. 1974. Jurassic. In RAyneR, D. H. \& Hemingway, J. E. (eds) The Geology and Mineral Resources of Yorkshire. Yorkshire Geological Society Occasional Publication, 2, 161-223.

HEMINGWAY, J. E. \& KNox, R. W. O'B. 1973. Lithostratigraphical nomenclature of the Middle Jurassic strata of the Yorkshire Basin of north-east England. Proceedings of the Yorkshire Geological Society, 39, 527-535.

HeMingWaY, J. E. \& OWEN, J. S. 1975. William Smith and the Jurassic coals of Yorkshire. Proceedings of the Yorkshire Geological Society, 40, 297-308.

Hesselbo, S. P. \& Jenkyns, H. C. 1995. A comparison of the Hettangian to Bajocian successions of Dorset and Yorkshire. In: TAYLon, P. D. (ed.) Field Geology of the British Jurassic. Geological Society, London, 105-150.

HoGG, N. M. 1993. A palynological investigation of the Scalby Formation and adjacent strata (Ravenscar Group, Middle Jurassic) from the Cleveland Basin, North Yorkshire. Ph.D. Thesis, University of Sheffield.

IvENS, C. R. \& WATSON, G. G. 1994. Records of dinosaut footprints on the north east Yorkshire coast 1895-1993. Roseberry Publications, Middlesborough.

KANTOROwCZ, J. D. 1990. Lateral and vertical variations in pedogenesis and other early diagenetic phenomena, Middle Jurassic Ravenscar Group, Yorkshire. Proceedings of the Yorkshire Geological Sociery, 48, 61-74.

Kendald, P. F. 1908. Reptilian Footprints in the lower Oolites at Saltwick. The Naturalist, $619,384$.

Kendal, P. F, \& Wroot, H. E. 1924. The Geology of Yorkshire. Printed privately, Vienna.

KNOX, R. W. O'B., Howard, A. S., POWELl, J. H. \& VAN BuCHEM, F S. P. 1991. Lower and Middle Jurassic sediments of the Cleveland Basin, N. E. England: shallow marine and paralic facies seen in their sequence stratigraphic context. Field Guide, 5. Compiled for the 13th International Sedimentological Congress, Nottingham, U.K. 1990, British Sedimentological Research Group.

Konijnenburg-Van Cittert, J. H. A. \& Morgans, H. S. 1999. The Jurassic Flora of Yorkshire, Palaeontological Association Field Guide to Fossils, 8.

LEEDER, M. R. \& NAMT, M. 1979. Sedimentary models for the nonmarine Scalby Formation (Middle Jurassic) and evidence for late Bajocian/Bathonian uplift of the Yorkshire basin. Proceedings of the Yorkshire Geological Society, 42, 461-482.

IJVeRA, S. E. \& LeEder, M. R. 1981. The Middle Jurassic Ravenscar Group ('Deltaic Series') of Yorkshire: recent sedimentological studies as demonstrated during a Field Meeting, 2-3 May 1980. Proceedings of the Geologists' Association, 92, 241-250.

LOCKLEY, M. G. 1989. Summary and Prospectus. In: GILleTTE, D. D. \& Lockiey, M. G. (eds) Dinosaur Tracks and Traces. Cambridge University Press, Cambridge, 441-447.

LOCKLEY, M. G. 1991a. The dinosaur footprint renaissance. Modem Geology, 16, 139-160.

LOCKLEY, M. G. 1991b. Tracking Dinosaurs. Cambridge University Press, Cambridge.

LockLEY, M. G. 1998. The vertebrate track record. Nature, 396, $429-432$.

Lockley, M. G. \& ConRAD, K. 1989. The Paleoenvironmental Context, Preservation and Paleoecological Significance of Dinosaur Tracksites in the Western USA. In: GILlETTE, D. D. \& LockLEY, M. G. (eds) Dinosaur Tracks and Traces. Cambridge University Press, Cambridge, 121-134.

Lockiey, M. G. \& GilletTe, D. D. 1989. Dinosaur tracks and Traces: An Overview. In: Gillette, D. D. \& Lockley, M. G. (eds) Dinosaur Tracks and Traces. Cambridge University Press, Cambridge, 3-10

LOCKLEY, M. G. \& HUNT, A. P. 1995. Dinosaur tracks and other fossil footprints of the western United States. Columbia University Press, New York.

LOCKLEY, M. G. \& MEYER, C. 2000. Dinosaur tracks and other fossil footprints of Europe. Columbia University Press, New York.

Martinsson, A. 1970. Toponomy of trace fossils. In: CrIMEs, T. P. \& HarPer, J. C. (eds) Trace Fossils. Geological Joumal, Special Issue, 3, 323-330.

MCAllister, J. A. 1989. Subaqueous vertebrate footmarks from the upper Dakota Formation (Cretaceous) of Kansas, U.S.A. Occasional Papers, Museum of Natural History, University of Kansas, Lawrence, 127, 1-22.

MJøs, R. \& Prestholm, E. 1993. The geometry and organization of fluviodeltaic channel sandstones in the Jurassic Saltwick Formation, Yorkshire. Sedimentology, 40, 919-935.

Muøs, R., Walderhaug, O. \& Prestholm, E. 1993. Crevasse splay sandstone geometries in the Middle Jurassic Ravenscar Group of Yorkshire, UK. In: MARZO, M. \& PUIGDEFABREGAS, C. (eds) Alluvial Sedimentation. Special Publication of the International Association of Sedimentologists, 17, 167-184.

Moratalla, J. J., Garcia-Mondé, J., Santos, V. F., Lockley, M. G., SANZ, J, L. \& JMÉNEZ, S. 1994. Sauropod trackways from the Lower Cretaceous of Spain. Gaia, 10, 75-83.

Morgans, H. 1999. Lower and Middle Jurassic woods of the Cleveland Basin (North Yorkshire), England. Palaeontology, 42, 303-328.

Morgans, H., Hesselbo, S. P. \& SPICER, R. A. 1999. The seasonal climate of the Early-Middle Jurassic, Cleveland Basin, England. Palaios, 14, 261-272.

Morris, P. H. \& Coleman, B. E. 1990. The Aalenian to Callovian (Middle Jurassic). In: JENKINS, D. G. \& MurraY, J. W. (eds) Stratigraphical atlas of fossil Foraminifera (2nd edition). British Micropalaeontological Society Series, Ellis Horwood, Chichester, 189-236.

Mossman, D. J. \& SARJEANT, W. A. S. 1983. The Footprints of Extinct Animals. Scientific American, 248, 64-74.

NAMI, M. \& LEEDER, M. R. 1978. Changing channel morphology and magnitude in the Scalby Formation (M. Jurassic) of Yorkshire, England. In: Mial, A. D. (ed.) Fluvial sedimentology. Canadian Society of Petroleum Geologists, Memoir, 5, $431-440$

OLSEN, P. E. 1980. Fossil great lakes of the Newark Supergroup in Now Jersey. In- MANSPEIZER, W. (ed.) Field Studies of New Jersey Geology and Guide to Field Trips. New York State Geological Association, 52nd Annual Meeting, Rutgers University, 352-398.

PALLIAN, R. B. \& RIDING, J. B. 2000. A palynological investigation of the Lower and lowermost Middle Jurassic strata (Sinemurian to Aalenian) from North Yorkshire, UK. Proceedings of the Yorkshire Geological Society, 53, 1-16. 
PARsons, C. F. 1977. A stratigraphic revision of the Scarborough Formation. Proceedings of the Yorkshire Geological Society, 41, $203-222$.

Pickerill, R. K. 1994. Nomenclature and taxonomy of invertebrate trace fossils In: Donovan, S. K. (ed.) The Palaeobiology of Trace Fossils. John Wiley \& Sons, Chichester, $3-42$.

RAWson, P. F. \& WRIGHT, J. K. 1995. Jurassic of the Cleveland Basin, North Yorkshire. In: TAYLOR, P. D. (ed.) Field Geology of the British Jurassic. Geological Society, London, 173-208.

Rawson, P. F. \& WRIGHT, J. K. 2000. The Yorkshire Coast. Geologists' Association Guide, 34.

Richardson, L. 1912. The Lower Oolitic rocks of Yorkshire. Proceedings of the Yorkshire Geological Society, 17, 184-215.

RIDING, J. B. 1984. A palynological investigation of Toarcian to early Aalenian strata from the Blea Wyke area, Ravenscar, North Yorkshire. Proceedings of the Yorkshire Geological Society, 45, 109-122.

RIDING, J. B. \& WRIGHT, J. K. 1989. Palynostratigraphy of the Scalby Formation (Middle Jurassic) of the Cleveland basin, north-east Yorkshire. Proceedings of the Yorkshire Geological Society, 47, 349-354.

Romano, M. \& Whyte, M. A. 1987. A limulid trace fossil from the Scarborough Formation (Jurassic) of Yorkshire; its occurrence, taxonomy and interpretation. Proceedings of the Yorkshire Geological Society, 46, 85-95.

Romano, M. \& WHYTE, M. A. 1990. Selenichnites, a new name for the ichnogenus Selenichnus. Proceedings of the Yorkshire Geological Society, 48, 221.

Romano, M. \& Whyte, M. A. 1996. Fossils explained 16: Trace fossils 3 - dinosaur tracks. Geology Today, 12, 75-79.

Romano, M. \& WHYTE, M. A. 2003. The first record of xiphosurid (arthropod) trackways from the Saltwick Formation, Middle Jurassic of the Cleveland Basin, Yorkshire. Palaeontology, 46. 257-269.

Romano, M., Whyte, M. A. \& ManNing, P. L. 1999. New sautopod dinosaur ichnites from the Saltwick Formation (Middle Jurassic) of the Cleveland Basin, Yorkshire. Proceedings of the Yorkshire Geological Society, 52, 361-369.

Romer, A. S. 1966. Vertebrate Paleontology. Chicago Press.

SAMPSON, S. 1997. Dinosaur Combat and Courtship. In-FARLow, J. O. \& BRETT-SURMAN, M. K. (eds) The complete dinosaur. Indiana University Press, Bloomington \& Indianapolis, 383-393.

Santos, V. F., Lockiey, M. G., Meyer, C. A., Carvalho, J., Galopim De Carvalho, A. M. \& Moratalla, J. J. 1994. A new sauropod tracksite from the Middle Jurassic of Portugal. Gaia, 10, $5-13$.

SARIEANT, W. A. S. 1970. Fossil footprints from the middle Triassic of Nottinghamshire and the middle Jurassic of Yorkshire. Mercian Geologist, 3, 269-282.

SARJEANT, W. A. S. 1974. A history and bibliography of the study of fossil vertebrate footprints in the British Isles. Palaeogeography, Palaeoclimatology, Palaeoecology, 16, 265-378.

SARJEANT, W. A. S. 1975. Fossil tracks and impressions of vertebrates. In: Frey, R. W. (ed.) The Study of Trace Fossils. Springer Verlag, Berlin, 283-324.
SEILACHER, A. 1964. Sedimentological classification and nomenclature of trace fossils. Sedimentology, 3, 253-256.

SHEPPARD, T. 1908. Footprints in a Yorkshire Sandstone. The Naturalist, 619, 300-301.

Sylvester-BRAdLEY, P. C. 1953. A stratigraphical guide to the fossil localities of the Scarborough district. The Natural History of the Scarborough District, 1, 19-48.

Thulborn, T. 1990. Dinosaur Tracks. Chapman \& Hall, London.

Thulborn, R. A. \& WADE, M. 1979. Dinosaur stampede in the Cretaceous of Queensland. Lethaia, 12, 275-279.

Thulborn, R. A. \& WADE, M. 1989. A Footprint as a History of Movement. In: GilleTTE, D. D. \& LoCKLEY, M. G. (eds) Dinosaur Tracks and Traces. Cambridge University Press, Cambridge, $51-56$.

Tresise, G. R. 1996. Sex in the Footprint Bed. Modem Geology, 12, 22-26.

Tresise, G. \& SARJEANT, W. A. S. 1997. The Tracks of Triassic Vertebrates. Fossil Evidence from North-West England. The Stationery Office: London.

TUCKER, M. E. \& BURCHETTE, T. P. 1977. Triassic dinosaur footprints from South Wales: their context and preservation. Palaeogeography, Palaeoclimatology, Palaeoecology, 22, 195-208.

Weishampel, D. B., Dodson, P. \& Osmolska, H. 1990. The Dinosauria. University of California Press.

WHYTE, M. A. \& RoMANO, M. 1981. A footprint in the sands of time. Journal of the University of Sheffield Geological Society, 7, 323-330.

Whyte, M. A. \& Romano, M. 1993. Footprints of a sauropod dinosaur from the middle Jurassic of Yorkshire. Proceedings of the Geologists' Association, 104, 195-199.

WHYTE, M. A.\& ROMANo, M. 1994. Lower-Middle Jurassic sequences between Whitby and Saltwick. In: SCRUTTON, C. (ed.) Yorkshire rocks and landscape - A field guide. Ellenbank Press, Maryport, Cumbria, 158-164.

WHYTE, M.A.\& RoMano, M. 1995. Probable sauropod footprints from the middle Jurassic of Yorkshire, England. Gaia, 10, 15-26.

Whyte, M. A. \& Romano, M. 2001. Probable stegosaurian dinosaur tracks from the Saltwick Formation (Middle Jurassic) of Yorkshire, England. Proceedings of the Geologists' Association, 112, $45-54$.

Whyte, M. A. \& Romano, M. 2002 (for 2001). A dinosaur ichnocoenosis from the Middle Jurassic of Yorkshire, U.K. Ichnos, 8 , 223-234.

Williamson, W. C. 1837. On the Distribution of Fossil Remains on the Yorkshire Coast from the Lower Lias to the Bath Oolite inclusive. Transactions of the Geological Society, Series 2, 5, 223-242.

WRIGHT, J. K. 1968. The stratigraphy of the Callovian rocks between Newtondale and the Scarborough coast, Yorkshire. Proceedings of the Geologists' Association, 79, 363-399.

Wright, J. K. 1977. The Cornbrash Fommation (Callovian) in North Yorkshire and Cleveland. Proceedings of the Yorkshire Geo. logical Society, 41, 325-346.

Revised manuscript received: 2 nd November 2002 